\title{
Distribution of strong earthquake input energy in tall buildings equipped with damped outriggers
}

\author{
M. Morales-Beltran ${ }^{1,2}$ (D) | G. Turan ${ }^{3}$ | U. Yildirim ${ }^{4} \mid$ J. Paul ${ }^{1}$
}

${ }^{1}$ Faculty of Architecture and the Built Environment, TU Delft, the Netherlands

${ }^{2}$ Faculty of Architecture, Yaşar University, Izmir, Turkey

${ }^{3}$ Department of Civil Engineering, Izmir Institute of Technology IYTE, Turkey

${ }^{4}$ Department of Civil Engineering, Eastern Mediterranean University, Famagusta, North Cyprus

\section{Correspondence}

Mauricio Morales-Beltran, Faculty of Architecture and the Built Environment, TU Delft, the Netherlands.

Email: m.g.moralesbeltran@tudelft.nl

\section{Present Address}

Mauricio Morales-Beltran, Faculty of Architecture, Yaşar University, Universite Caddesi, No.35-37, 35100 Bornova, İzmir, Turkey.

\section{Funding information}

Comisión Nacional de Investigación Científica y Tecnológica, Grant/Award Number: 72100284

\begin{abstract}
Summary
The seismic design of optimal damped outrigger structures relies on the assumption that most of the input energy will be absorbed by the dampers, whilst the rest of the structure remains elastic. When subjected to strong earthquakes, nevertheless, the building structure may exhibit plastic hinges before the dampers begin to work. In order to determine to which extent the use of viscously damped outriggers would avoid damage, both the host structure's hysteretic behaviour and the dampers' performance need to be evaluated in parallel. This article provides a parametric study on the factors that influence the distribution of seismic energy in tall buildings equipped with damped outriggers: First, the influence of outrigger's location, damping coefficients, and rigidity ratios core-to-outrigger and core-to-column in the seismic performance of a 60-story building with conventional and with damped outriggers is studied. In parallel, nonlinear behaviour of the outrigger with and without viscous dampers is examined under small, moderate, strong, and severe long-period earthquakes to assess the hysteretic energy distribution through the core and outriggers. The results show that, as the ground motion becomes stronger, viscous dampers effectively reduce the potential of damage in the structure if compared to conventional outriggers. However, the use of dampers cannot entirely prevent damage under critical excitations.
\end{abstract}

\section{KEYWORDS}

damped outrigger, energy distribution, hysteretic energy, strong earthquakes, tall buildings, viscous damper

\section{1 | INTRODUCTION}

Outrigger systems consist of a series of cantilever truss beams or shear walls connecting the building core with the perimeter columns. As a result, the axial forces acting at the end of the outriggers help the reduction of the total deflection of tall buildings by increasing the restoring moment. Dampers have been introduced between the perimeter columns and the outriggers, resulting in an increase in the overall damping of the building, instead of an increase of static stiffness and strength. ${ }^{[1]}$ A well-known first implementation of this system in twins' 60 -story buildings is reported in Willford and Smith. ${ }^{[2]}$ Park et al. ${ }^{[3]}$ reported the installation of damped outriggers in a 68-story tower in South Korea. In a recent review, ${ }^{[4]}$ Smith reported two more applications of damped outriggers in tall buildings. All the authors point out that the addition of supplementary damping systems not only reduced the overall vibration response, but also construction costs.

Numerical and experimental studies have been conducted to extend these damper-based control capabilities towards an improved reduction of the dynamic response, ${ }^{[3,5-7]}$ including seismic scenarios. ${ }^{[8-17]}$ However, few studies explore the performance of damped outriggers under strong earthquake motion. Generally, studies are based on the use of peak ground acceleration (PGA) values up to $0.4 \mathrm{~g}$, whereas strong earthquakes may exhibit PGAs of about $1.0 \mathrm{~g}$. At the same time, most of the research done focuses on the reduction of the response in terms of peak values. Only few studies consider the combined influence of the intensity, frequency content, and duration of these strong earthquakes in the control performance of the damped outriggers. Hence, the need of an energy-based assessment of the building response by which the damage potential can be quantified.

Energy-based design methods have the potential to address both the effect of the duration of the earthquakes and the hysteretic behaviour of the structure. ${ }^{[18]}$ As stated by Uang and Bertero, ${ }^{[19]}$ an energy-based design method is based on the premise that the energy demand during an earthquake can be predicted as the energy supplied by the structure can be therefore defined. A correct design implies that the energy supply 
is larger than the energy demand. In the case of tall buildings equipped with damped outriggers, a correct design also relies on the arguable assumption that the dampers will absorb the total earthquake energy whilst the rest of the structure remains elastic during the seismic event. Nevertheless, under strong or severe earthquake-induced motion, some plastic hinges or failures may be produced in the structure before the dampers can dissipate the total input energy. Therefore, the hysteretic behaviour of the host structure needs to be evaluated along the dampers' performance in order to determine how the earthquake input energy is distributed through all the components.

Few studies on seismic energy distribution in tall buildings can be found in related literature-see for example Zhou et al., Beiraghi et al., and Lu

et al. ${ }^{[16,20,21]}$ Most of the reviewed research on seismic energy distributions concentrates on buildings with natural periods up to $4 \mathrm{~s}{ }^{[22,23]}$ even when supplemental damping devices are attached to the building structure. ${ }^{[24-26]}$ To the authors' knowledge, there are no studies on energy distributions related to the use of viscous dampers in outrigger structures.

This article provides a parametric study to assess the distribution of seismic energy in tall buildings equipped with viscous damped outriggers, that is, with outriggers that have one or more viscous damper installed between their ends and the perimeter columns. The aim of this explorative study is to determine (a) which parameters influence the distribution of seismic input energy through the building structure and how such energy is eventually dissipated by both the host structure and the viscous dampers; (b) if strong earthquake input energy can be completely dissipated by the viscous dampers in such a way that the level of damage and/or failure of the structure is reduced to zero; and (c) which strategies will extend the elastic response threshold of a tall building equipped with viscous dampers and subjected to strong earthquake ground motions.

The strategy to assess the distribution of earthquake energy in tall buildings equipped with viscous damped outriggers and subjected to strong earthquake-induced motion is based on the numerical study of 60-story buildings equipped with conventional and damped outriggers, respectively. First, a parametric study addresses the influence of building natural period, position of the outrigger, damping coefficient, and rigidity ratios core-to-outrigger and core-to-columns in the control performance of the outrigger structures. Second, the interdependency between structural properties of tall buildings equipped with damped outriggers and ground motion characteristics is examined under three long-period earthquake records. These ground motions are scaled to small, moderate, strong, and severe earthquakes to determine the nonlinear threshold.

\section{I NONLINEAR BUILDING MODELS WITH CONVENTIONAL AND DAMPED OUTRIGGERS}

The analytical models used in this study are based on the existing Shangri-La building in Manila, Philippines, as described by Willford and Smith. ${ }^{\text {[2] }}$ Both core and outrigger were modelled using nonlinear settings, as they are expected to be the major sources of hysteretic energy dissipation. Perimeter columns, on the contrary, were modelled with elastic elements. Unless the use of a small cross-sectional area is combined with a large core bending deformation, column strength demand can be safely expected to be smaller than $70 \%$ of the yielding strength, even under severe earthquake loading, and thus remaining within the elastic threshold.

The modelling of the core wall requires the definition of plastic regions, usually located at the base zone. However, related studies have pointed out the formation of plastic hinges in other places, such as at the middle height ${ }^{[27]}$ or at the regions adjacent to outriggers. ${ }^{[28]}$ However, by modelling some portions of the structure with elastic elements, the energy dissipation associated with yielding and cracking might not be captured. Moreover, the study in Beiraghi et al. ${ }^{[20]}$ demonstrated that the distribution of inelastic energy along the building's height is strongly related to the amount of plastic hinges used in the modelling of the core. The analytical model described here, therefore, considers the use of general nonlinear material models throughout almost the whole finite element (FE) model as specified by Diana-FEA software. ${ }^{[29]}$

The Shangri-La building possesses 8 2-story deep outriggers distributed in pairs at each side. The 2D FE model described here considers 2 outriggers per side, each pair modelled as a single $7 \mathrm{~m}$ high outrigger. Although the actual 60-story Shangri-La building features wall-type or deep beam outriggers, a truss girder model for the outrigger configuration is proposed in this study as it enables a more efficient use of the space for functional purposes. In terms of modelling, outriggers are usually defined as infinite rigid and mass less. ${ }^{[7,11,30]}$ This simplifies the analyses because it is assumed that by attaching an infinite rigid outrigger to the main core, both will rotate the same amount. However, there are two main reasons for this study not following this assumption: (a) the outriggers are designed with larger stiffness compared to the other stories, whose effect provokes changes of stiffness in the building, and thus make it more vulnerable under strong earthquakes. ${ }^{[12]}$ Assuming an infinite rigid outrigger may lead to incorrect results of the building's behaviour during nonlinear transient analyses; and (b) the assumption of an infinite rigid outrigger is incompatible with a seismic energy distribution-based analysis. Moreover, it has been suggested that the outrigger may be the major plastic energy dissipation component in tall buildings. ${ }^{[21]}$ Hence, the stiffness of the outrigger is considered in this study.

Two types of building models were used for the analyses: one building with conventional outrigger systems and the other with damped outriggers (Figure 1). The first model, hereafter called "fixed outrigger," comprises the core, the outriggers, and the perimeter columns; the second model, hereafter called "damped outrigger," comprises the core, outriggers, perimeter columns, and viscous dampers installed between the outriggers and the columns. The use of two analytical models offers a comparative framework-given by the fixed outrigger-to which the improvements given by the addition of dampers may be compared-and thus validated. In the models, both building plan and distribution of resistant elements are symmetrical, so the lateral stiffness in two orthogonal directions is assumed to be equal; equally assumed is the lack of significant torsional effects, and therefore, a planar model is used for simplification purposes. Secondary structural components, such as slabs, steel frames, were not considered 

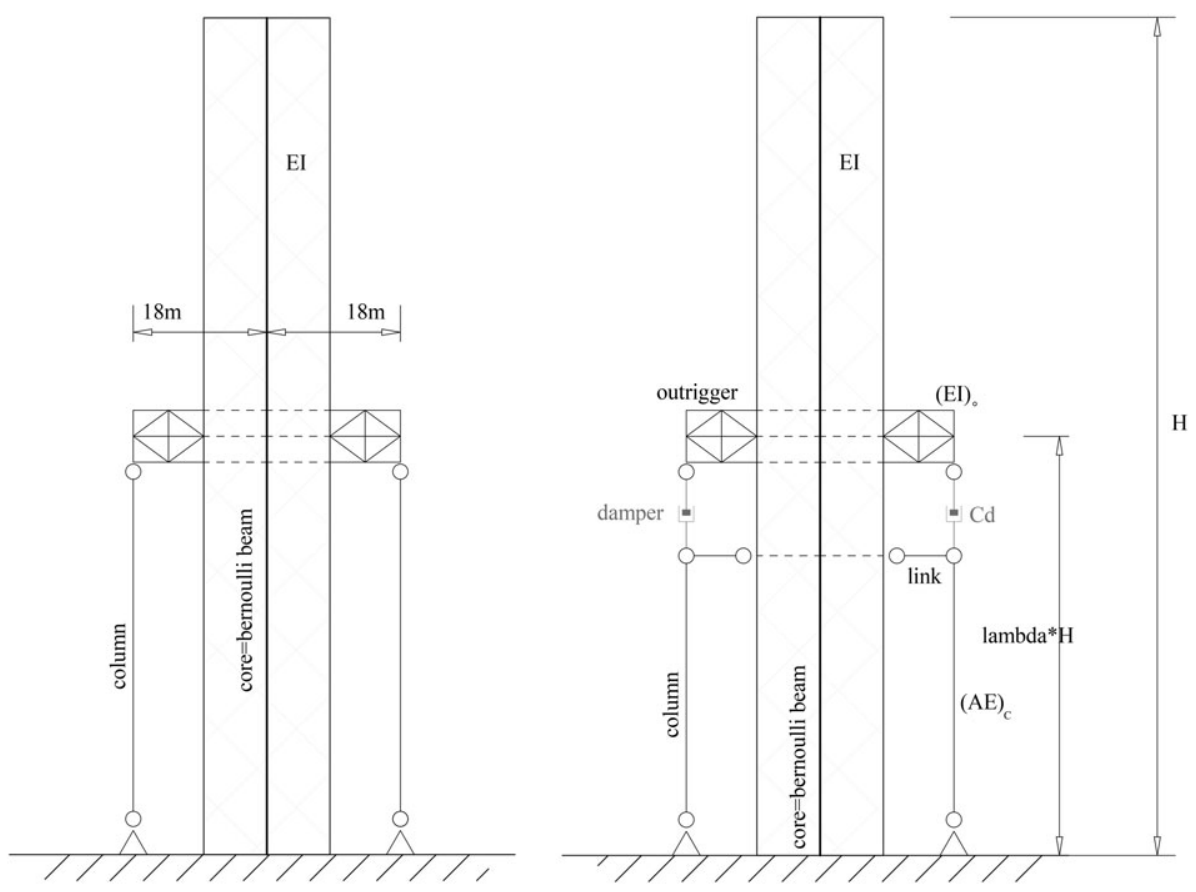

FIGURE 1 Simplified fixed and damped outrigger building models

in the models under the assumption that they do not contribute significantly to the total lateral stiffness of the structure. The equivalent mass of these building elements was added as mass node to the structural mode, at the corresponding story height. The core is an $18 \times 18 \mathrm{~m}$ reinforced concrete tube, with a constant thickness of $0.75 \mathrm{~m}$. The FE model of the core is modelled as a Bernoulli-Euler cantilever beam type, due to the fact that the potential failure of the core tube is dominated by bending deformation. Reinforced concrete perimeter columns are also modelled following the design of the existing 60-story building in Manila. In summary, the model comprises 255 DOF.

The main structural elements used for the modelling in Diana-FEA are depicted in Figure 2, wherein only half of the model is showed for simplification. For modelling both core and outrigger, the L7BEN nonlinear structural element was used as it accounts for geometric and physic nonlinearities in the analysis. Diana-FEA calculates strains and stresses in the so-called "stress points" of beam elements. In L7BEN elements, the stress points are equivalent with the integration points (Figure 3). Despite the core is modelled as box, in 2D settings, Diana-FEA merges the integration zones parallel to the analysed direction ( $X$ in the figure), so the beam presents an I-shape cross-section. Each quadrilateral integration zone contains three integration points. At any given node, the stress produced by axial forces is accounted for at integration point (intp) 8 , whilst the tensile/compressive stresses produced by bending moment are considered at intp 3 and intp 4 . In addition to these nonlinear settings, node masses were modelled using PT3T; the columns and the story beam required for equilibrium conditions with L6BEN; and the viscous damper with SP2TR.

\section{1 | Plasticity models for core and outrigger elements}

The total strain crack model is used to define the nonlinear behaviour of the concrete, which is characterized by tensile cracking and compressive crushing. This constitutive model is based on total strain and describes the tensile and compressive behaviour of the concrete based on a bilinear stress-strain relationship as defined in Eurocode $2 .{ }^{[31]}$ Concrete strength class is C35/45 and reinforcement steel bars are $400 \mathrm{MPa}$.

For the outrigger, the plasticity model of Von Mises is used to define the nonlinear properties of the steel. An elasto-plastic model is considered for its constitutive behaviour, that is, strain hardening effect is not taken into account. The reserve of ductility given by the hardening post-yield is considered as a safe increase in the design. Properties of the steel are derived from Eurocode 3. ${ }^{\text {[2] }}$

\subsection{Consideration of lateral confinement and uniform distribution of longitudinal reinforcement in the modelling of the core}

Initially, the influences of neither the lateral confinement nor the lateral cracking were considered in the reduction of strength after cracking. The resulting increase in ductility due to the confinement was accounted as an extra safety margin. Nevertheless, the use of this model may fail to define to which extent the non-accounted increase of the wall strength would influence the energy dissipation mechanisms of the structure, especially after cracking. Therefore, a second model considering the effect of both lateral confinement and lateral cracking was developed. In 


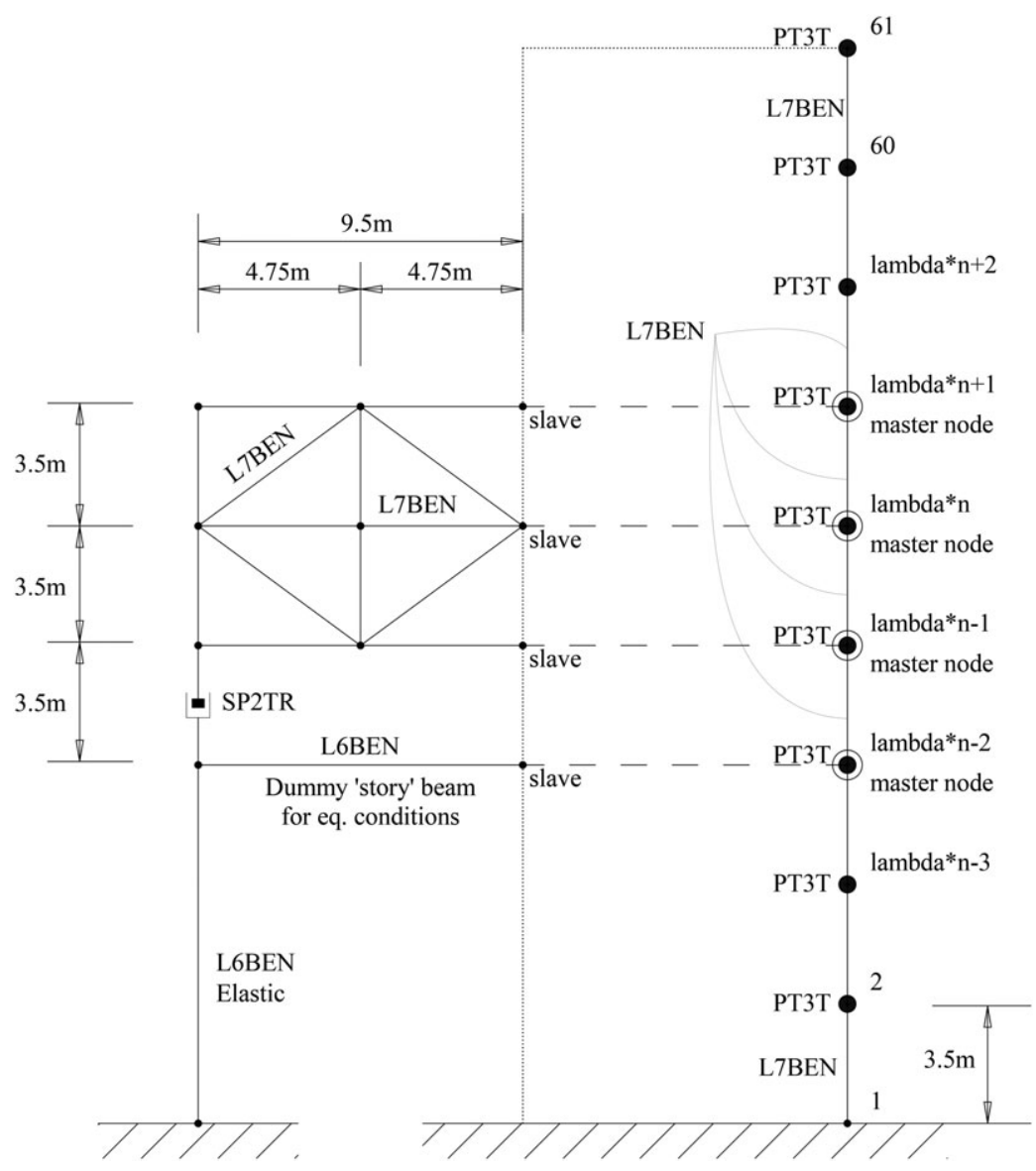

FIGURE 2 Structural elements used in the nonlinear modelling of the damped outrigger in Diana-FEA
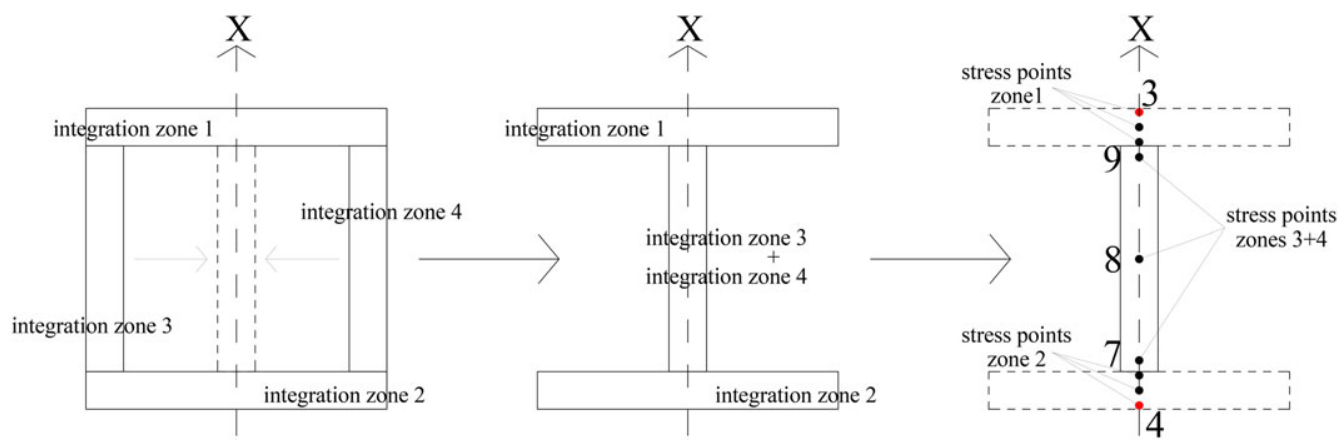

FIGURE 3 Conversion scheme box-to-I shape cross section of the core. Integration/stress points are depicted for each integration zone

Diana-FEA, the lateral confinement is modelled "through a pre-strain concept in which the lateral expansion effects are accounted for with an additional external loading on the structure, ${ }^{\text {[29] }}$ according to the work of Selby and Vecchio. ${ }^{[29]}$ To test the influence of these modelling assumptions, results of nonlinear analyses using both models-with and without lateral confinement-had to be compared.

In a similar approach, the influence of the distribution of longitudinal steel reinforcement of the core along the height, in the nonlinear performance of the outrigger structure, was studied by proposing two models. One with $1 \%$ vertical reinforcement, uniformly distributed along the height, and another, where the maximum longitudinal reinforcement was provided only over the lower section of the building (six floors) and decreased towards the upper levels. This distribution was defined following the capacity flexural strength design envelope as proposed by Boivin and Paultre ${ }^{[33]}$ with a minimum reinforcement ratio $=0.25 \%{ }^{[34]}$ All models considered the reduction of the Poisson effect after cracking.

Four numerical models were then developed (Table 1) to represent the 60-story building with a single damped outrigger and damper's damping coefficient equals to $1.5 \mathrm{E}+08 \mathrm{Ns} / \mathrm{m}$. Inherent damping ratio $=2 \%$. Analyses included the modification of outrigger location between 0.4 and $0.9 \mathrm{H}$.

Figure 4 is the representative of the story drifts under outrigger locations between 0.4 and 0.9 . According to the results obtained, it is possible to conclude that there is no difference in the response of the outrigger structure under four different earthquake magnitudes, in terms of 
TABLE 1 Correlation of modelling parameters organized per model

\begin{tabular}{lll} 
Model denomination & Lateral confinement? & Uniform distribution of longitudinal reinforcement? \\
\hline lu & Yes & Yes \\
In & Yes & No \\
nu & No & Yes \\
$n n$ & No & No \\
\hline
\end{tabular}
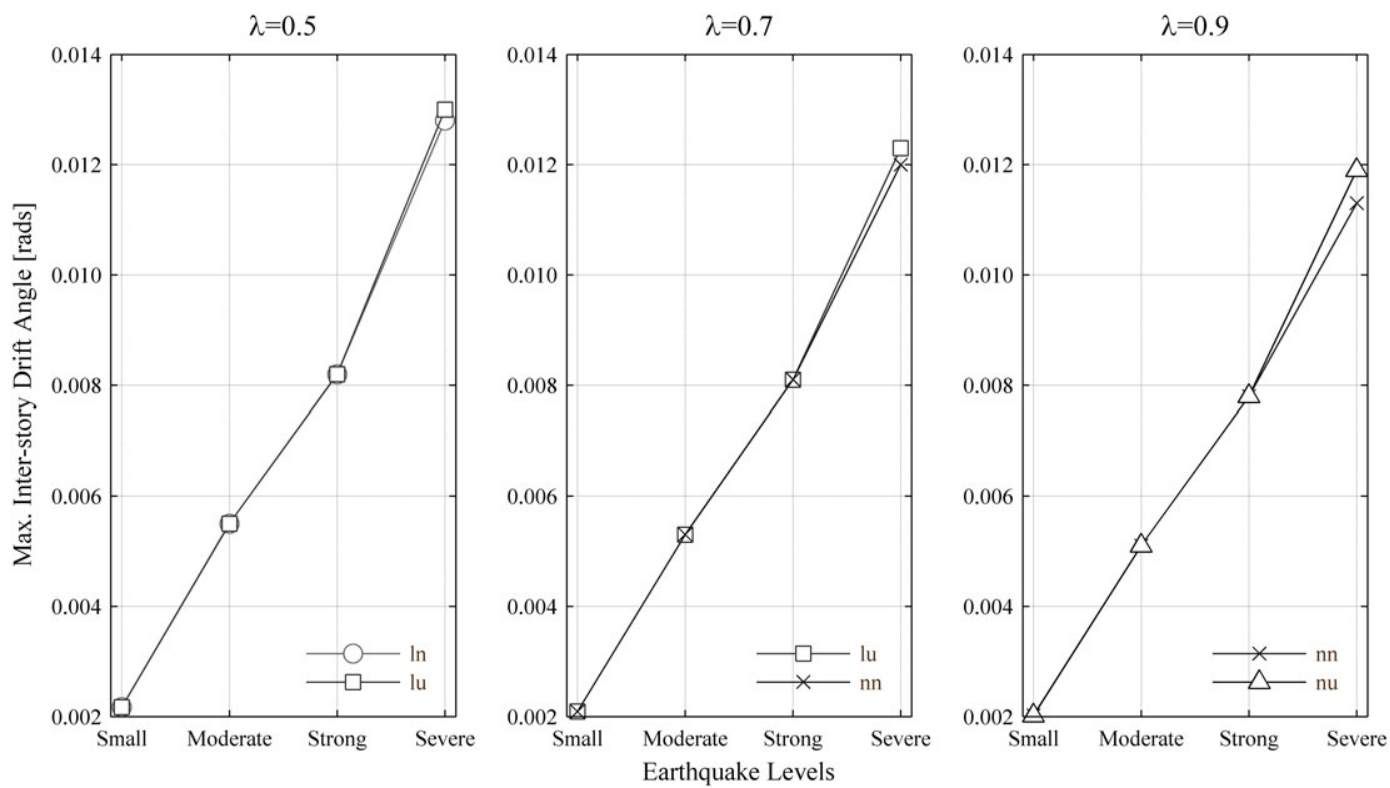

FIGURE 4 Comparison between maximum inter-story drift ratios of the four core modelling parameters-depicted in pairs-under four intensity levels of $1940 \mathrm{El}$ Centro earthquake, at different outrigger locations $(\lambda)$. Under strong and severe levels, the response is inelastic

considering lateral confinement (or not) in the modelling of the core. Contrarily, the use of non/uniform distribution of longitudinal steel bar reinforcement modifies the response, although not substantially (variation $<2 \%$ ).

Similar trend is observed when energy distribution is considered. For example, in Figure 5, it can be noticed that the use of lateral confinement does not substantially modify the distribution of input energy (variation $<0.0000001 \%$ ). Nevertheless, the same plot shows that modelling the core with and without a uniform distribution of longitudinal reinforcement will do affect the energy distribution (variation $<12 \%)$. Because the modification of these modelling parameters make no difference when the response is elastic, in Figure 6 , only the inelastic response is shown. Here, the variation on the energy distributions is accounted by $\Delta_{e}$, which is equal to the difference between the peak energy values of the structure with non-uniform $(n)$ and with uniform $(u)$ longitudinal reinforcement distribution, that is, $\Delta_{e}=P_{e a k} E_{n}-P_{e a k}$ $\mathrm{E}_{\mathrm{u}}$. The time-history analyses were performed with the outrigger at locations between 0.4 and $0.9 \mathrm{H}$. Under strong earthquake levels, $\Delta_{\mathrm{e}}$ between dampers and damping energies remains within a $0.5 \%$, whereas input and hysteretic energies display variations in the order of 2.0\%. Under severe earthquake level, damping and input energies display a difference of about $10 \%$, dampers energy almost a $20 \%$, and hysteretic energy, a difference larger than $25 \%$.

Given the aforementioned results, the FE models described in this study, unless stated otherwise, do consider the contribution of lateral confinement and use a non-uniform distribution of longitudinal reinforcement in the modelling of the core.

\section{3 | Long-period earthquakes}

Because this study focuses on tall buildings, transient response analyses are considered more meaningful to provide insights on the response if the structure is subjected to long-period earthquakes. To obtain these, the ratio peak ground acceleration-to-peak ground velocity (PGA/PGV) of several ground motion records was obtained and earthquakes with ratios smaller or equal to eight were included (Table 2). The ground accelerations of the earthquakes of Izmit-Kocaeli, El Centro, and New Zealand are displayed in Figure 7. These records were systematically scaled down/up in order to critically asses the distribution of seismic input energy in the structure (Table 3). The scaling was based on the earthquakes' PGV, which is more meaningful for the assessment of structures whose expected improved performance relies on the addition of velocity- 


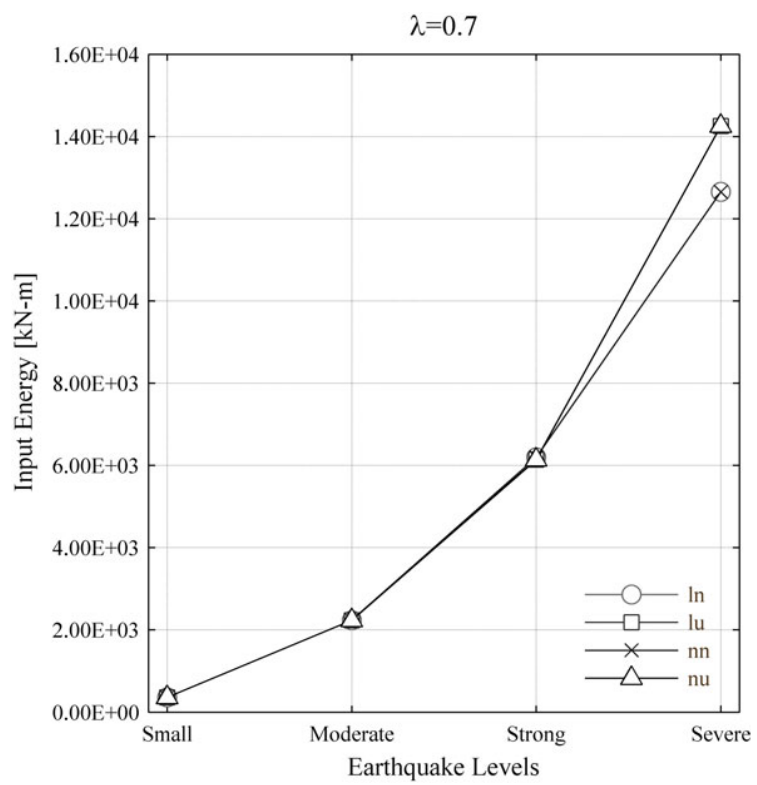

FIGURE 5 Input energy in the outrigger structure, modelled with combined core parameters, when subjected to four intensity levels of 1940 El Centro earthquake
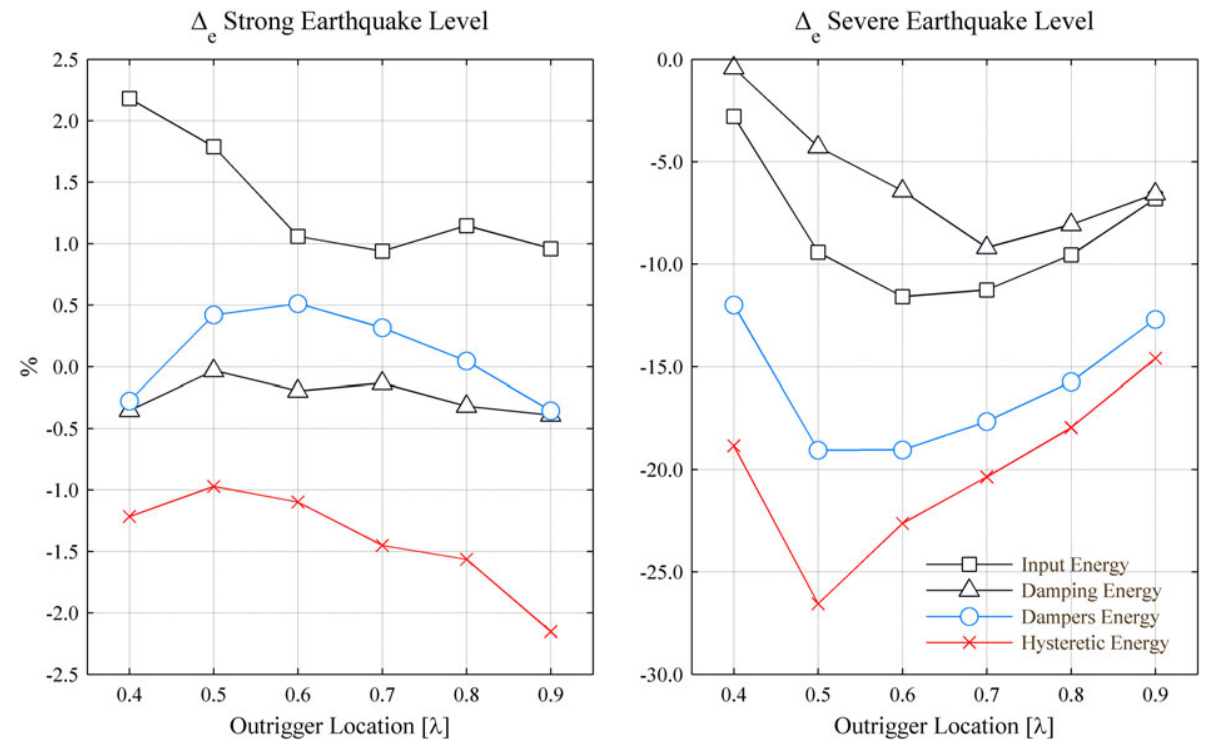

FIGURE $6 \quad \Delta_{\mathrm{e}}(\%)$ between energy distributions obtained with a non-uniform $(\mathrm{n})$ and uniform (u) distribution of longitudinal reinforcement under strong and severe intensity levels of 1940 El Centro earthquake. Note that vertical scale is different for each plot

TABLE 2 Characteristics of the long-period earthquakes used in this study

\begin{tabular}{llllllllc} 
Earthquake & Comp. & Station & Date & Mw & $\begin{array}{l}\text { Epicentre } \\
\text { distance }(\mathrm{km})\end{array}$ & PGA (cm/s $\left.{ }^{2}\right)$ & PGV (cm/s) & $\begin{array}{l}\text { Ratio } \\
\text { PGA/PGV }\end{array}$ \\
\hline Izmit-Kocaeli & 90 & Yarimca & August 17, 1999 & 7.4 & 17.1 & 230.16 & 90.5 & 2.54 \\
El Centro & 270 & No.117 & May 18, 1940 & 6.9 & 16.9 & 210.14 & 36.92 & 5.69 \\
New Zealand & N55 W & Greendale & September 03, 2010 & 7.0 & 6.9 & 737.73 & 94.51 & 7.81
\end{tabular}

Note. $\mathrm{PGA}=$ peak ground acceleration; $\mathrm{PGV}=$ peak ground velocity .

dependant devices. The elastic threshold was set at velocity amplitudes up to $50 \mathrm{~cm} / \mathrm{s}$ and classified as moderate earthquakes, whereas velocity amplitudes less than $25 \mathrm{~cm} / \mathrm{s}$ were classified as small earthquakes; velocity amplitudes between 50 and $100 \mathrm{~cm} / \mathrm{s}$ as strong earthquakes; and velocity amplitudes beyond $100 \mathrm{~cm} / \mathrm{s}$ as severe earthquakes. These earthquake records were downloaded via the Strong-motion Virtual Data Center. ${ }^{[35]}$ 

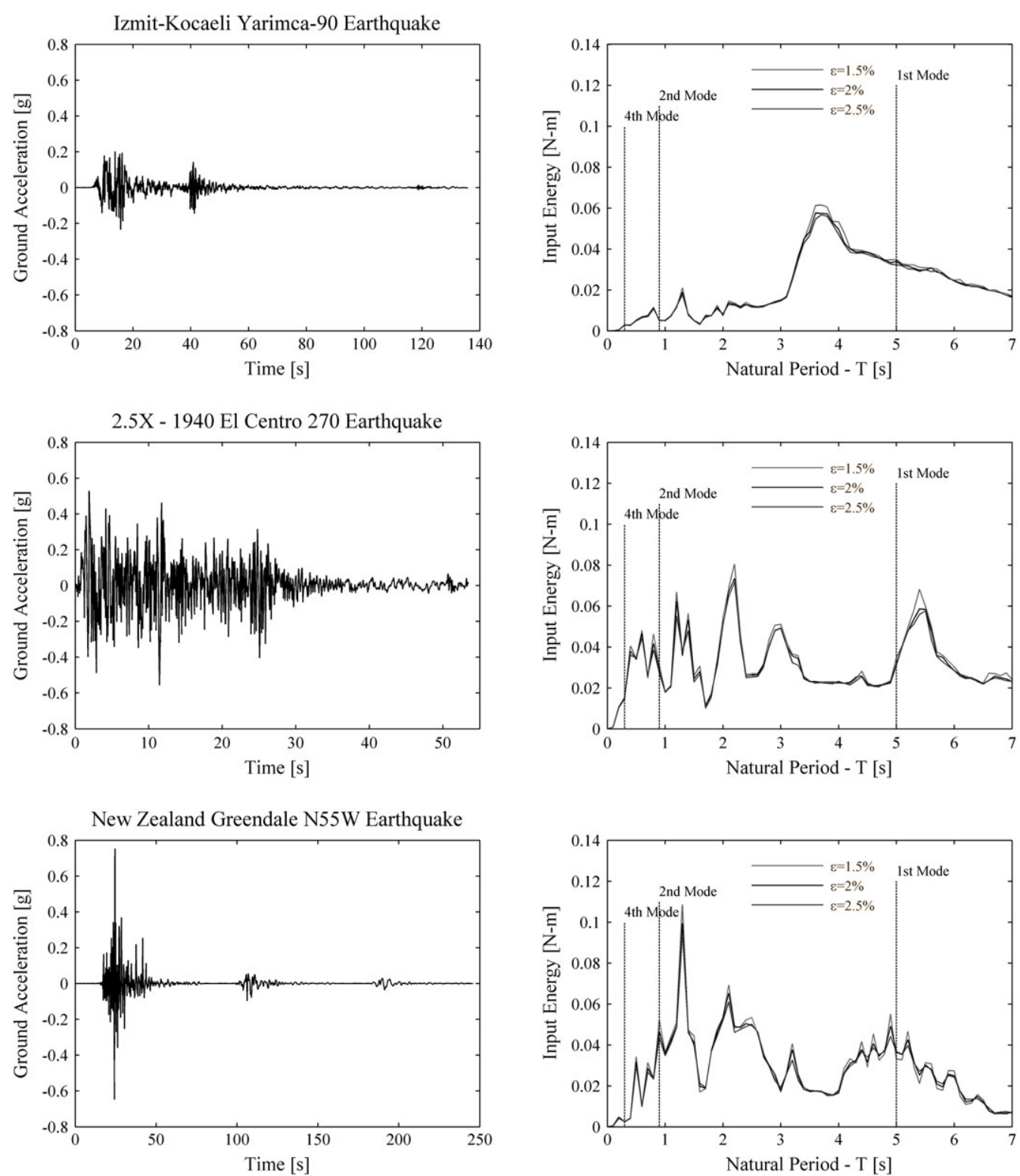

FIGURE 7 Scaled strong ground motion records used in this study and their associated energy input spectra. Displayed accelerations caused damage to the building

TABLE 3 Scaled PGA-PGV of four earthquake levels after selected ground motion records

\begin{tabular}{|c|c|c|c|c|c|c|c|c|}
\hline \multirow{2}{*}{$\begin{array}{l}\text { Earthquake } \\
\text { records }\end{array}$} & \multicolumn{4}{|c|}{ PGA $\left(\mathrm{cm} / \mathrm{s}^{2}\right)$} & \multicolumn{4}{|c|}{ PGV (cm/s) } \\
\hline & Small & Moderate & Strong & Severe & Small & Moderate & Strong & Severe \\
\hline Izmit-Kocaeli & 57.54 & 115.08 & 230.16 & 345.24 & 22.63 & 45.25 & 90.50 & 135.75 \\
\hline New Zealand & 184.43 & 368.87 & 737.73 & 1844.33 & 23.63 & 47.26 & 94.51 & 236.28 \\
\hline
\end{tabular}

Note. PGA = peak ground acceleration; PGV = peak ground velocity.

\section{I ASSESSMENT OF THE DISTRIBUTION OF SEISMIC ENERGY IN A TALL BUILDING}

The equation governing dynamic response of a multi-degree of freedom system, such as a tall building, can take the form

$$
M \ddot{x}+C \dot{x}+K x=-M \Gamma \ddot{x},
$$

where $M$ and $K$ are the diagonal lumped mass and stiffness matrices, respectively; $C$ is the damping matrix computed considering Rayleigh damping; $x$ is the column vector of relative displacements of the node mass with respect to ground; $\ddot{x}_{g}$ is the one-dimensional ground acceleration; and $\Gamma$ is 
coefficient vector for ground accelerations. If Equation 1 is multiplied by the transpose of the relative velocity vector $\dot{x}(t)$, and integrated over the entire duration of the ground motion $(0-t)$, the equation of motion can be expressed in terms of the energy balance equation as follows:

$$
\int_{0}^{t} \dot{x}^{\top} M \ddot{x} d t+\int_{0}^{t} \dot{x}^{\top} C \dot{x} d t+\int_{0}^{t} \dot{x}^{\top} K x d t=-\int_{0}^{t} \dot{x}^{\top} M \Gamma \ddot{x}_{g} d t
$$

The first term in Equation 2 is the relative kinetic energy $\left(E_{K}\right)$, which can be written as

$$
E_{K}=\int_{0}^{t} \dot{x}^{\top} M \ddot{x} d t=\frac{1}{2} \dot{x}^{T} M \dot{x}
$$

The second term in Equation 2 is the inherent damping energy of the structure $\left(E_{D}\right)$, and it can be written as

$$
E_{D}=\int_{0}^{t} \dot{x}^{T} C \dot{x} d t
$$

Because viscous dampers are attached to the outrigger structure, $E_{D}$ includes also the energy dissipated by these passives devices, so that the total damping energy becomes

$$
E_{D_{-} \text {total }}=E_{D}+E_{\text {dampers }}=\int_{0}^{t} \dot{x}^{T} C \dot{x} d t+\int_{0}^{t} \dot{x}^{T} \Lambda C_{d} \dot{x}_{d}^{k} d t
$$

where $\Lambda$ is the location matrix of the dampers-associated with the outrigger location $\lambda-, C_{d}$ is the damping coefficient of the damper, $\dot{x}_{d}$ is the velocity across the damper, and $\mathrm{k}$ is the exponent value that controls the linear/nonlinear behaviour of the damper.

The third term in Equation 2 is the total absorbed energy $\left(E_{A}\right)$, defined as

$$
E_{A}=\int_{0}^{t} \dot{x}^{\top} K x d t
$$

Because the structure absorbs energy by a combination of elastic and inelastic mechanisms, $E_{A}$ can also be defined as

$$
E_{A}=E_{S}+E_{H}
$$

where $E_{S}$ and $E_{H}$ are the elastic strain and hysteretic energy, respectively. By considering $[K]$ as the pre-yield stiffness matrix of the structure, $E_{S}$ can be written as

$$
E_{S}=\frac{1}{2} \dot{x}^{\top} K x
$$

The hysteretic energy $E_{H}$ is given by

$$
E_{H}=E_{H-\text { force }}+E_{H-\text { bending }}+E_{H-\text { shear }}
$$

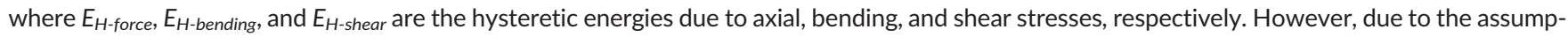
tion of a Bernoulli beam in the modelling of the core, stresses and strains derived from shear forces can be neglected, and thus $E_{H}$ is reduced to

$$
E_{H}=\int f_{s}\left(x-x_{\text {yield }}\right) d x+\int M_{b}\left(\theta-\theta_{\text {yield }}\right) d \theta
$$

where $f_{s}$ is the restoring force, $M_{b}$ is the bending moment, and $\theta$ is the associated angle of rotation.

Finally, the last term in the Equation 2 is the total energy introduced in the system as a consequence of the ground motion produced by an earthquake. This energy is equivalent to the energy input at foundation of the building as given by

$$
E_{I}=-\int_{0}^{t} \dot{x}^{\top} M \ddot{x}_{g} d t
$$

Replacing Equations 3, 5, 6, 7, and 11 in Equation 1, the energy balance equation for a multi-degree of freedom system is given by

$$
E_{K}+E_{D}+E_{\text {dampers }}+E_{S}+E_{H}=E_{l}
$$

As noted, the energy balance equation has been defined in relative terms instead of absolute ones. According to Uang and Bertero, ${ }^{\text {[19] }}$ damping energy, strain energy, and hysteretic energy terms are uniquely defined, irrespective of what method is used. Given the interest on quantifying only the hysteretic and damping energies-including that derived from the dampers as well-the distinction between absolute and relative energy methods become less critical. ${ }^{[18,36]}$ In addition, the authors believe that the use of relative energy terms instead of absolute ones is more meaningful for engineering applications. Chopra ${ }^{[37]}$ and Bruneau and Wang, ${ }^{[36]}$ as cited in Khashaee et al., ${ }^{[18]}$ support this approach as "internal forces within a structure are computed using relative displacements and velocities." 


\section{1 | Methodology}

According to Equation 12, the distribution of seismic energy is based on the demand of total input energy- $\mathrm{E}_{\mathrm{l}}$. Nonetheless, kinetic and elastic strain energies tend to zero at the end of the vibration, whilst its maximum values take place at the beginning of the earthquake motion. Hence, they are not affected by the duration of strong motion, ${ }^{[18]}$ and it is valid to assume that, by the end of the motion, $E_{1}$ is mostly defined by the combined effect of damping energies $\left(E_{D}+E_{\text {dampers }}\right)$ and hysteretic energy $\left(E_{H}\right)$ dissipation. On the other hand, maximum damping and hysteretic energies permit to evaluate the energy dissipation capacity to limit structural damage. Therefore, insights on how these energies are related may be more significant for the assessment of the seismic energy distribution in the damped outriggers than spotting single-based performances. These relationships can be expressed by (a) the ratio hysteretic-to-input energy $\xi_{\text {hyst-to-inp, }}$, defined as the hysteresis energy ratio $E_{H} / E_{1} ;(b)$ the ratio

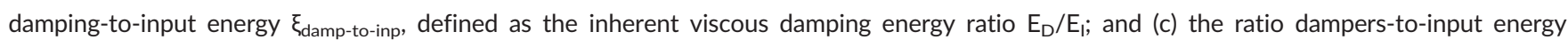

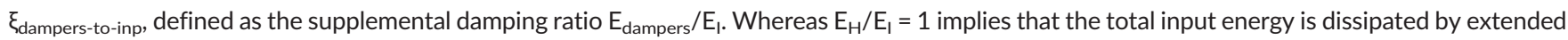
damage and/or failure of the structure, a value of zero implies no structural damage. ${ }^{[24]}$ Furthermore, $E_{H} / E_{1}=0$ implies elastic behaviour in all the elements of the structure during the entire ground motion. Because this latter case is highly unlikely under strong and severe earthquake levels, the purpose of the following studies is not only determining which parameters mainly affects the seismic response of damped outrigger structures, but also how such influence is exerted. The ultimate goal, nevertheless, is to determine if the energy dissipation due to hysteresis can be fully replaced by energy dissipated through the action of viscous dampers.

\section{I PARAMETRIC STUDY ON THE FACTORS AFFECTING THE PERFORMANCE OF DAMPED OUTRIGGERS}

The following parametric study was set by modification of the core-damping ratio ( $\zeta)$; outrigger location $(\lambda)$ and rigidity ratio core-to-outrigger ( $\rho_{\text {cto }}$ ); dampers' damping coefficient $\left(C_{d}\right)$; and rigidity ratio core-to-column $\left(\rho_{c t c}\right)$. Models including combinations of these parameters were subjected to small, moderate, strong, and severe earthquake levels of the 1940 El Centro ground motion.

\section{1 | Preliminary design and modal shapes}

The outrigger building structure was initially designed to meet the target performance objectives for a $0.4 \mathrm{~g}$ strong earthquake-induced motion, as defined by the Equivalent Static Lateral Force method described in the Chilean Seismic Code-NCh.433. ${ }^{[38]}$ Following engineering practice, a two stories deep design provided adequate bending and shear stiffness to the outriggers. The steel profile sections used in the outrigger model were numerically studied to facilitate an outrigger's ductile behaviour under a loading force of about $3.75 \mathrm{E}+07$ [N]. Such load represents the equivalent force per damper for a $0.4 \mathrm{~g}$ PGA earthquake, under consideration of the outrigger stiffness contribution to the restoring moment. ${ }^{[39]}$

Following design approaches developed by Tan et al., Taranath, and Smith and Coull ${ }^{[7,30,40]}$ outriggers were preliminarily located at mid-height of the building, that is, at the 30th story. However, effective mass participation in X direction (Table 4) shows that the building with outriggers behaves similarly to fixed-free beam under bending vibration, wherein the effective modal mass of the first and second modes are 0.6131 and 0.1883 of the total mass, respectively. This suggests that, given the predominance of the first mode, the optimal position of the outrigger to reduce the lateral displacements is at $0.66 \mathrm{H}$, that is, at the effective modal height. For convenience, the initial location was set at $0.7 \mathrm{H}$.

When the effective mass participation in $Y$ direction is considered (Table 5), the third mode has more than $81 \%$ of the effective mass participation becoming the predominant mode of the response in the vertical direction. Modal shapes of 17 modes (up to $30 \mathrm{~Hz}$ ) of the building with fixed and damped outriggers were obtained using Diana-FEA. Because frequency content of the earthquakes larger than $30 \mathrm{~Hz}$ does not significantly affect the response, only Eigen-frequencies within that range were further considered. The modal shapes depicted in Figure 8 correspond to the predominant ones for parametric variations in the outrigger location and rigidity ratios core-to-column and core-to-outrigger. These parametric variations will be addressed in the next sections.

TABLE 4 Effective mass participation in $\mathrm{X}$ direction

\begin{tabular}{lllllll} 
& Period $(\mathrm{s})$ & & Eff. mass TX & \multicolumn{2}{c}{ Cumulative \% } \\
\hline Mode & Fixed & Damped & Fixed & Damped & Fixed & Damped \\
1 & 4.99 & 5.10 & $4.98 \mathrm{E}+07$ & $4.94 \mathrm{E}+07$ & 61.4 & 61.3 \\
2 & 0.85 & 0.82 & $1.53 \mathrm{E}+07$ & $1.53 \mathrm{E}+07$ & 80.3 & 80.3 \\
4 & 0.30 & 0.29 & $5.09 \mathrm{E}+06$ & $5.13 \mathrm{E}+06$ & 86.6 & 86.7 \\
5 & 0.16 & 0.15 & $2.49 \mathrm{E}+06$ & $2.54 \mathrm{E}+06$ & 89.7 & 89.7 \\
7 & 0.10 & 0.12 & $3.26 \mathrm{E}+04$ & $2.27 \mathrm{E}+01$ & 89.8 \\
9 & 0.09 & 0.09 & $1.48 \mathrm{E}+06$ & $1.39 \mathrm{E}+06$ & 91.5 & 91.6 \\
\hline
\end{tabular}


TABLE 5 Effective mass participation in $Y$ direction

\begin{tabular}{lllllll} 
& Period (s) & & Eff. mass TY & & Cumulative \% \\
\hline Mode & Fixed & Damped & Fixed & Damped & Fixed & Damped \\
3 & 0.39 & 0.38 & $6.52 \mathrm{E}+07$ & $6.50 \mathrm{E}+07$ & 80.5 & 80.7 \\
\hline 6 & 0.13 & 0.13 & $7.57 \mathrm{E}+06$ & $7.23 \mathrm{E}+06$ & 89.9 & 89.7 \\
\hline 8 & 0.10 & 0.12 & $2.97 \mathrm{E}+05$ & $5.54 \mathrm{E}+05$ & 90.2 & 90.4 \\
\hline
\end{tabular}
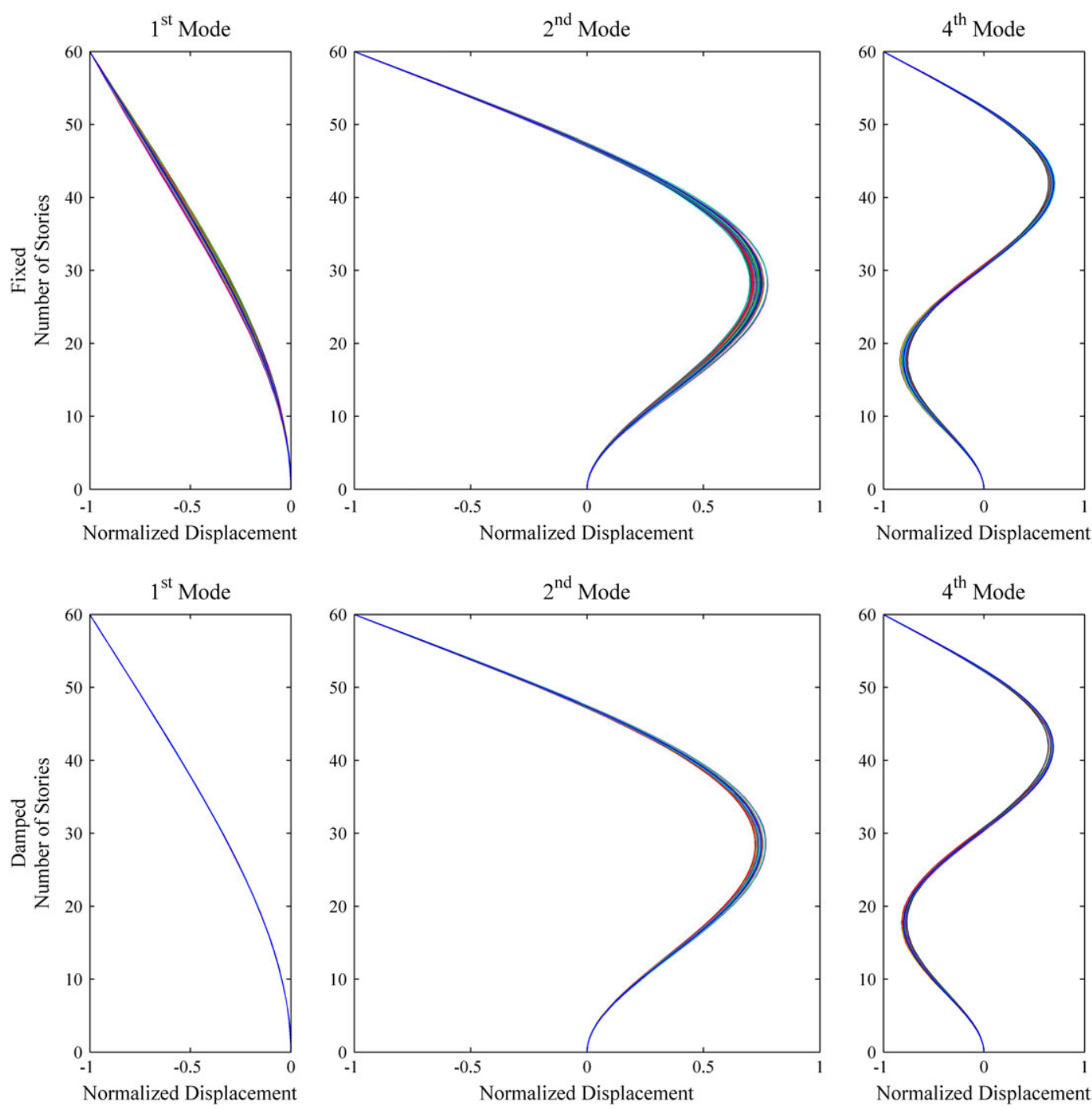

FIGURE 8 Predominant mode shapes of the fixed (upper row) and damped (lower row) outrigger system depicting variations due to the combined influence of outrigger location and rigidity ratios core-to-outrigger and core-to-column $(9 \times 5 \times 5$ parameters $=225$ modal shapes in each plot $)$

\subsection{Outrigger location $(\lambda)$}

The influence of the outrigger location in the increase of the inherent damping ratio $\zeta$ was studied by assuming a range of locations between 0.1 and 0.9 of the total height of the building, under free-vibration analyses. The outrigger location is described in terms of a non-dimensional parameter $\lambda$, such that location of the outrigger $=\lambda^{*} \mathrm{H}$, hence $\lambda=0.1-0.9$. Inherent damping ratio $\zeta$, assumed as equivalent viscous damping coefficient, was calculated using Rayleigh damping with values $=1.5 \%, 2.0 \%$, and $2.5 \%$. Then the optimal damping ratio $\zeta_{\text {OPT }}$ was computed under free vibration using logarithmic decrement technique. The case of the damped outrigger with $\zeta=2 \%$ is shown in Figure 9 . Considering optimal dampers size, $\zeta_{\text {OPT }}$ are displayed when $\lambda=0.6-0.8$. However, before and beyond the region defined by the optimal dampers' damping coefficients $\left(C_{d}\right)$, the use of $\lambda=0.4-0.9$ display similar trends. In addition, regardless the dampers size (damping coefficient), $\lambda<0.4$ has less effect on improving the overall damping ratio of the building, if compared to values of $\lambda>=0.4$. This observation is in agreement with the study of Huang and Takeuchi $^{[5]}$ and suggests that an optimal location of the outrigger $\left(\lambda_{\mathrm{OPT}}\right)$ is somewhere between 0.4 and 0.9 . It should be noticed, nevertheless, that 


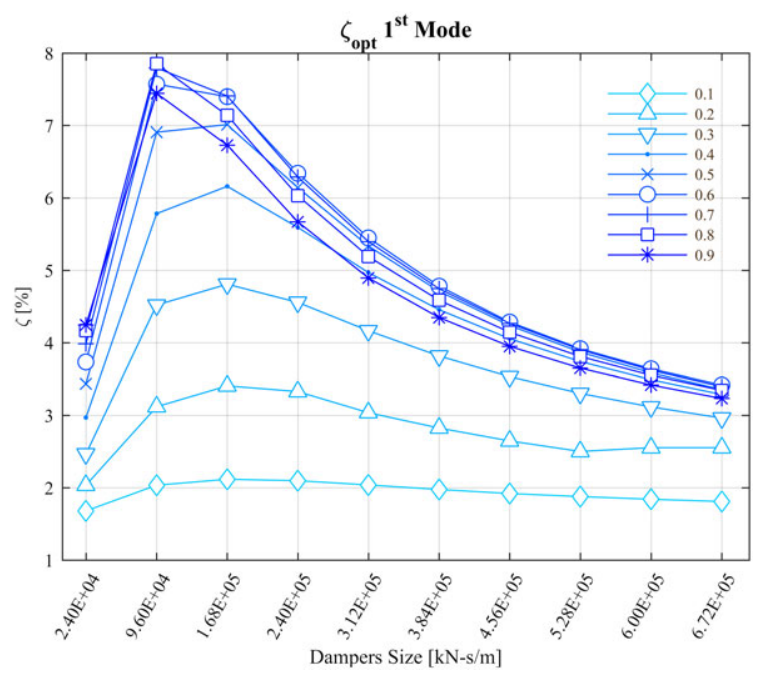

FIGURE 9 Increased $\zeta$ due to the combined influence of $\lambda(0.1-0.9)$ and dampers size, under free vibration

the optimal damping varies with the mode, so no single outrigger location will lead to reduce the response of all the modes to its minimum. ${ }^{\text {[41] }}$ Hence, this optimal range of $\lambda$ is hereafter considered under the assumption of the first mode predominance.

Although it has been suggested that damping ratio may exert a larger influence on the structural performance, ${ }^{[5]}$ peak responses may not be optimally reduced by assuming a $\lambda_{\mathrm{OPT}}$ based on the increase of the damping ratio. If, for a given earthquake level, the peak inter-story drift at each of the selected range of outrigger locations $\lambda$ is plotted, then the inter-story drift is reduced as $\lambda$ increases (Figure 10a). A similar trend is displayed when the peak inter-story velocities are accounted for, considering the first mode as predominant one (Figure 10c). In the case of the building drift (Figure 10b), a shift of the optimal location between $\lambda=0.8$ and $\lambda=0.6$ can be noticed when the response goes from elastic ( $\lambda=0.8$ ) to inelastic $(\lambda=0.7$ and 0.6 , for strong and severe earthquake levels, respectively). Peak lateral accelerations are comparatively reduced when $\lambda=0.5$, for the elastic case and under strong earthquake level. A shift to $\lambda=0.6$ occurs under severe motion (Figure $10 \mathrm{~d}$ ). Although drift responses are valid performance targets, in some cases it is more significant to control base forces or moments. For example, Wu and $\mathrm{Li}^{[42]}$ argue that an outrigger that is been designed stiff with the aim of reducing the top drift of a tall building, may create weak floors near the outrigger level. This may lead to shift the "optimal location" from a top drift-based control to an overturning moment-based control. In Figure 11 (right), it can be noticed that the overturning moment is comparatively reduced when $\lambda=0.5$, except for the severe level, where the optimal location is at $\lambda=0.7$. For reducing base shear

(a)

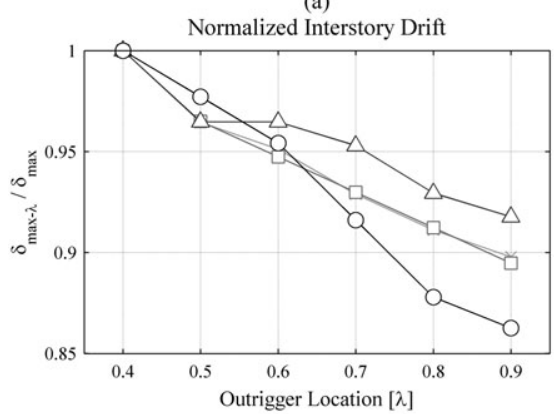

(c)

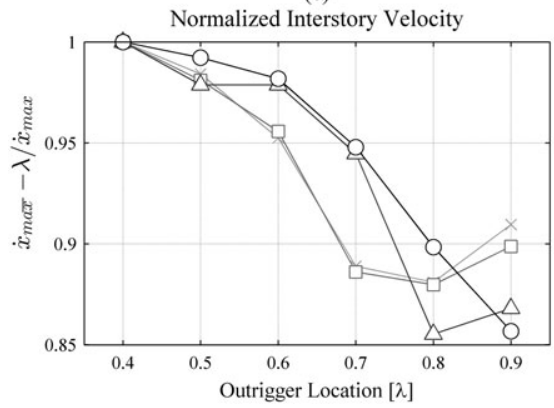

(b)

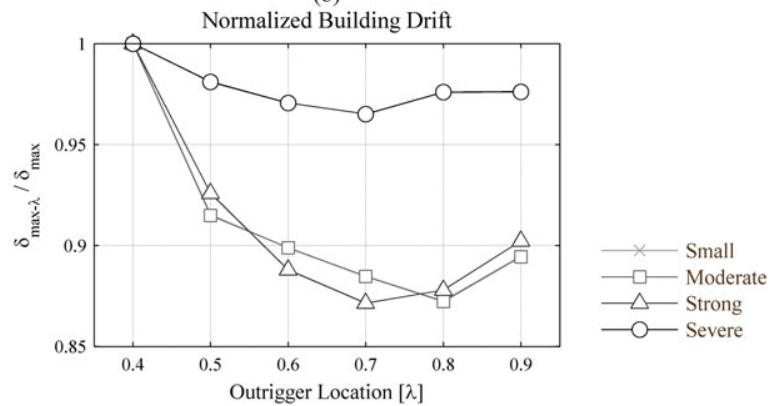

(d)

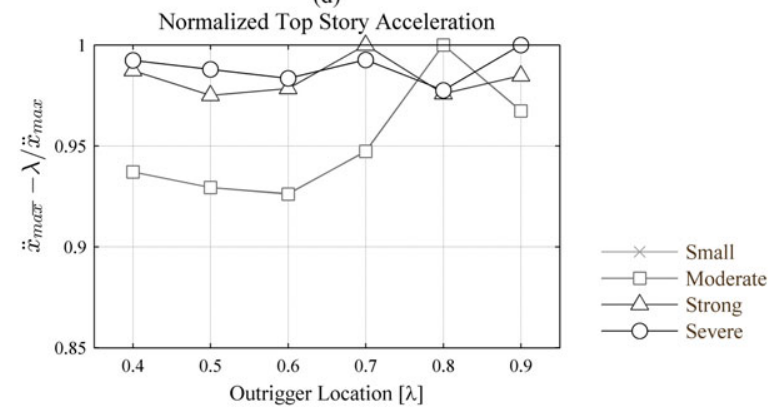

FIGURE 10 Normalized (actual/peak) drift, velocity, and lateral accelerations for different outrigger locations $(\lambda=0.4-0.9)$, of the damped outrigger building $\left(\zeta=2 \%, C_{d}=1.18 \mathrm{E}+05 \mathrm{kN}-\mathrm{s} / \mathrm{m}\right)$ subjected to four intensity levels of $1940 \mathrm{El}$ Centro earthquake 

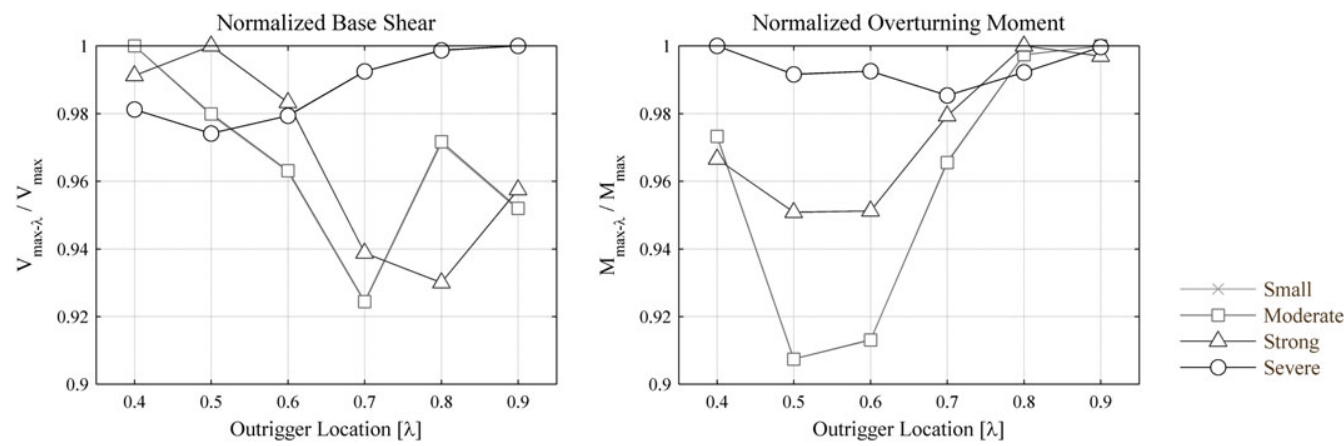

FIGURE 11 Normalized (actual/peak) base shear and overturning moments of the damped outrigger building $\left(\zeta=2 \%, C_{d}=1.18 \mathrm{E}+08 \mathrm{kN}-\mathrm{s} / \mathrm{m}\right)$, subjected to four intensity levels of $1940 \mathrm{El}$ Centro earthquake, with different outrigger locations $(\lambda=0.4-0.9)$

(Figure 11, left), $\lambda=0.7$ is the optimal location for the linear cases (small and moderate earthquake levels); $\lambda=0.8$ and 0.5 are the optimal locations under strong and severe motion, respectively. Although in apparent randomness, these observations reinforce the idea that $\lambda_{\mathrm{OPT}}$ is somewhere between 0.5 and 0.9 -and that the definition of "optimal" is strongly related to the target performance.

In Figure 12, the plots of input, damping, dampers, and hysteretic energies are separately displayed. Although the study of the energies alone cannot truly represent the way they are distributing through the structure, neither how are dissipated, the observation of these individual distributions gives insights over the influence of $\lambda$ in the global behaviour of the structure. For instance, when $\lambda=0.6$, the structure displays the lowest $E_{D}$ if compared to the $E_{D \max }$, for the first three earthquake levels. In addition, $\lambda=0.6$ implies the lowest $E_{1}$ even in the presence of hysteretic energy dissipation due to a strong earthquake. However, when $\lambda=0.6$, the energy dissipated by hysteresis is fairly closed to its peak occurring when the outrigger is located at $\lambda=0.7$. This means that an outrigger located at $\lambda=0.6$ will help to decrease the input energy, but if nonlinearities occur, most of that input energy may be dissipated by damage and not by damping. Furthermore, $\lambda=0.6$ is not an optimal location from the perspective of an efficient use of the viscous dampers either, during an elastic response. Under inelastic response, on the contrary, the peak energy dissipation by dampers takes place when $\lambda=0.7$, that is, dampers and hysteresis energy follow the same trend. This means that either the use of viscous dampers increases the damage in the structure or, given the reduction of $E_{l}$, dampers are indeed accounting for energy that otherwise would be dissipated by damage. These hypotheses are discussed in Section 5.

\subsection{Optimal dampers' damping coefficient $\left(C_{d}\right)$}

According to Equation 5, and location matrix $\wedge$ aside, the energy dissipated by the dampers is proportional to the product of $C_{d}$ and the velocity across the damper, modified by the exponent $\mathrm{k}$. This exponent can be varied between 0.15 and 2 , depending on the damper manufacturer's
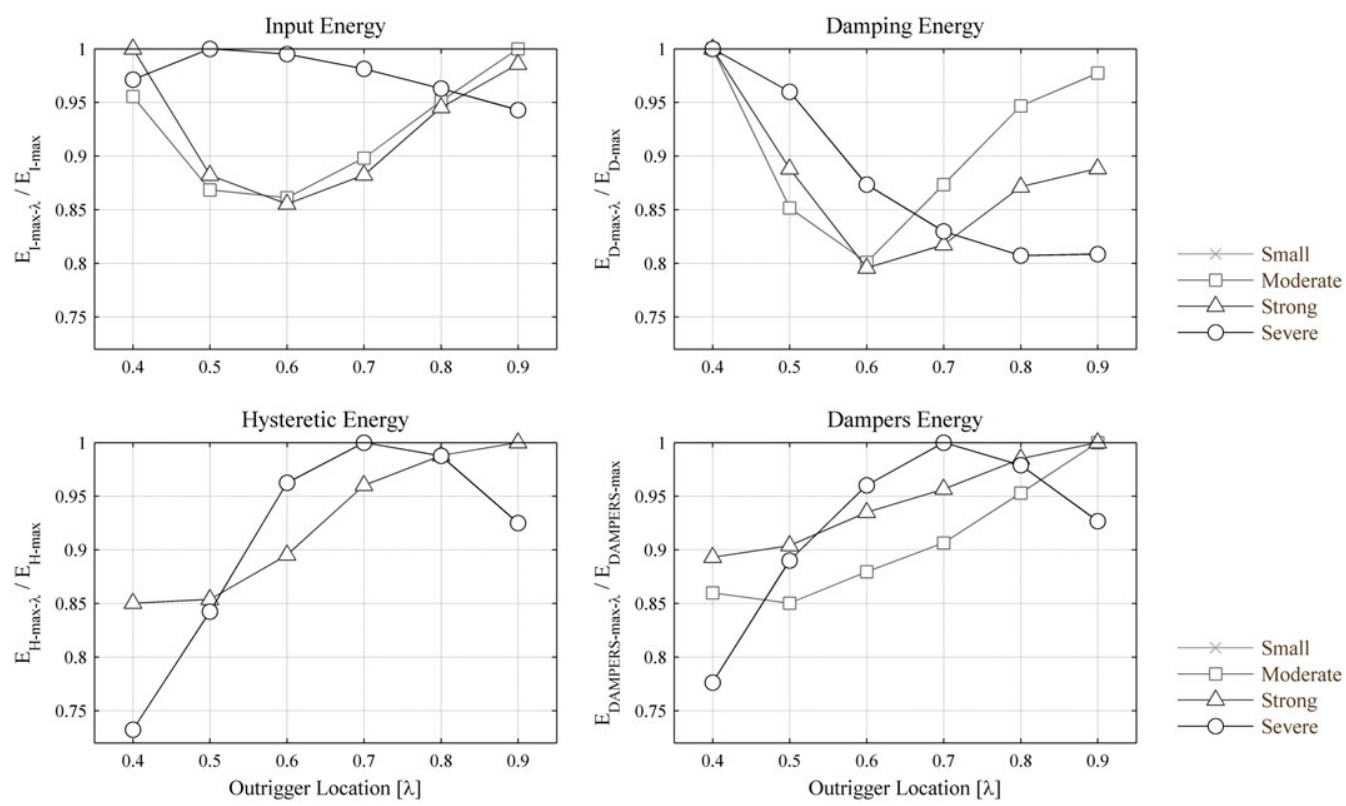

FIGURE 12 Normalized (actual/maximum) energy distributions of the outrigger structure $\left(\zeta=2 \%, C_{d}=1.18 \mathrm{E}+05 \mathrm{kN}-\mathrm{s} / \mathrm{m}\right)$ according to outrigger location $(\lambda=0.4-0.9)$ under four intensity levels of 1940 El Centro earthquake 
specifications. ${ }^{[4]}$ The use of $\mathrm{k}=1$, which is been suggested optimal for wind applications, ${ }^{[4,43]}$ implies that the damping forces provided by the damper will be proportional to the velocity. The use of $k \sim=2$ implies high forces at lower velocities, whereas the opposite occurs when lower values of $\mathrm{\kappa}$ are used. Under strong earthquake motions, the use of lower exponent might lead to the insensitivity of the dampers to low velocities, whereas the use of a linear exponent might lead to excessive damping forces, if compared to the wind damping. ${ }^{[4]}$ In this parametric study, however, $k$ is taken equals to one because comparatively excessive damping forces may help to understand the role of the outrigger's bending and shear stiffness in the distribution of seismic energy in the building structure. If, as a result of this assumption, the damping forces are indeed excessive, the use of a relief valve may help to avoid them. A relief valve allows the damper to work in a linear pattern till a relief load or pressure value is reached. At higher velocities then, the damper exerts low forces without affecting its performance at lower velocities.

In order to assess the performance of the oil viscous dampers attached to the outriggers, frequency response analyses were executed using damping coefficients ranging between $1.5 \mathrm{E}+05$ and $1.5 \mathrm{E}+11 \mathrm{Ns} / \mathrm{m}$. These values are arbitrary and were found by conducting sensitive analyses through a process of trial and error. It was observed that when $C_{d}<1.5 \mathrm{E}+05$, the system remains only damped by the core, that is, without any contribution of the outrigger whatsoever. Beyond $1.5 \mathrm{E}+11$, the structure behaves the same as with fixed outriggers. The observation of the vertical displacement response of the nodes outrigger-damper $(n O D)$ and damper-column $(n D C)$ in Figure 13 shows that when $C_{d}=1.5 \mathrm{E}+06$, the dynamic stiffness of the dampers is not enough to combine the axial stiffness given by the columns and the bending stiffness created by the core. Whereas $n O D$ displays a large vertical displacement, same displacement of $n D C$ is almost zero, indicating that they practically work separate from one another. When $C_{d}=1.5 \mathrm{E}+09$, the high dynamic stiffness "ties" the column to the outrigger so vertically they displace the same amount, that is, as if the structure had only conventional outriggers. Furthermore, the use of a low $C_{d}$ values introduces large stresses in the core and not in the perimeter column. In contrast, the use of large $C_{d}$ values not only leads to large stresses in the columns, but also in the vertical chords of the outrigger frame. ${ }^{[44]}$ In Figure 13, it can also be noticed that the frequency shift is insignificant if compared with the large variation of the $C_{d}$ values, and hence, it can be neglected. ${ }^{[5]}$

Based on the previous free vibration analyses, and according to the results displayed in Figure 14 , for a damped outrigger structure with $\zeta=2 \%$, the combined influence of $\lambda$ and $C_{d}$ will optimally increase the initial damping ratio when $\lambda=0.7$ and $C_{d}=1.18 \mathrm{E}+08 \mathrm{~N}$-s/m. Although this value may vary between different case studies, a numerical result is used here to illustrate the practical implications associated with providing the demanded supplemental damping. For example, commercially available viscous dampers are insufficient as they feature $C_{d}$ values in the order of $1.5 \mathrm{E}+06 \mathrm{~N}-\mathrm{s} / \mathrm{m}$. Alternatively, the number of dampers could be increased according to the space availability in the outrigger (Figure 15). If two dampers are installed per outrigger, $C_{d}$ increases up to $2.4 \mathrm{E}+07$ (eight outriggers with two dampers), and up to $4.8 \mathrm{E}+07$ if four dampers are installed at each outrigger arm. Because the number of dampers per outrigger cannot be likely increased beyond eight, the available supplemental
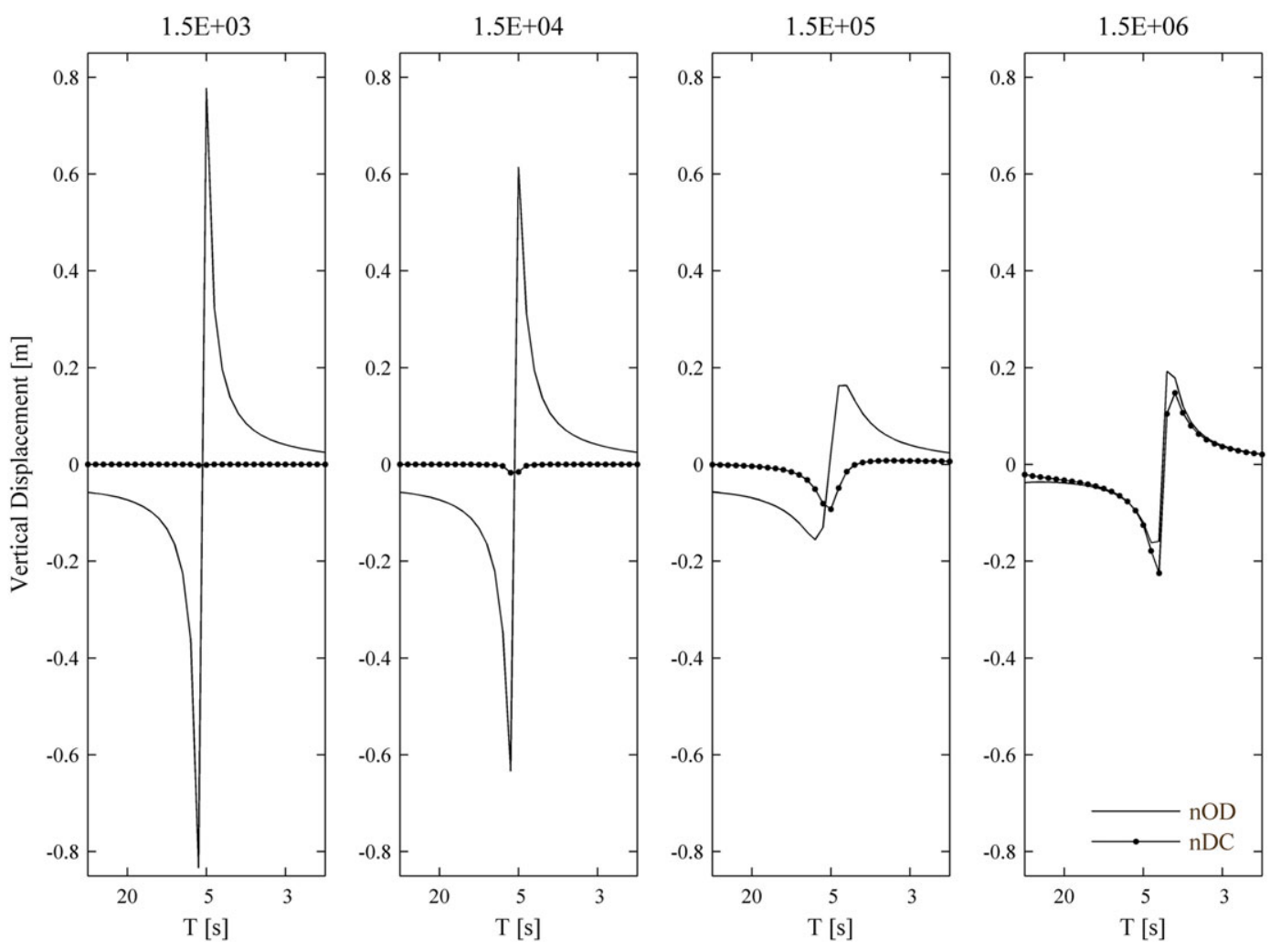

FIGURE 13 Frequency-based vertical displacements of the nodes outrigger-damper (nOD) and damper-column (nDC) for different damping coefficients of the viscous damper (in $\mathrm{kN}-\mathrm{s} / \mathrm{m}$ ) 


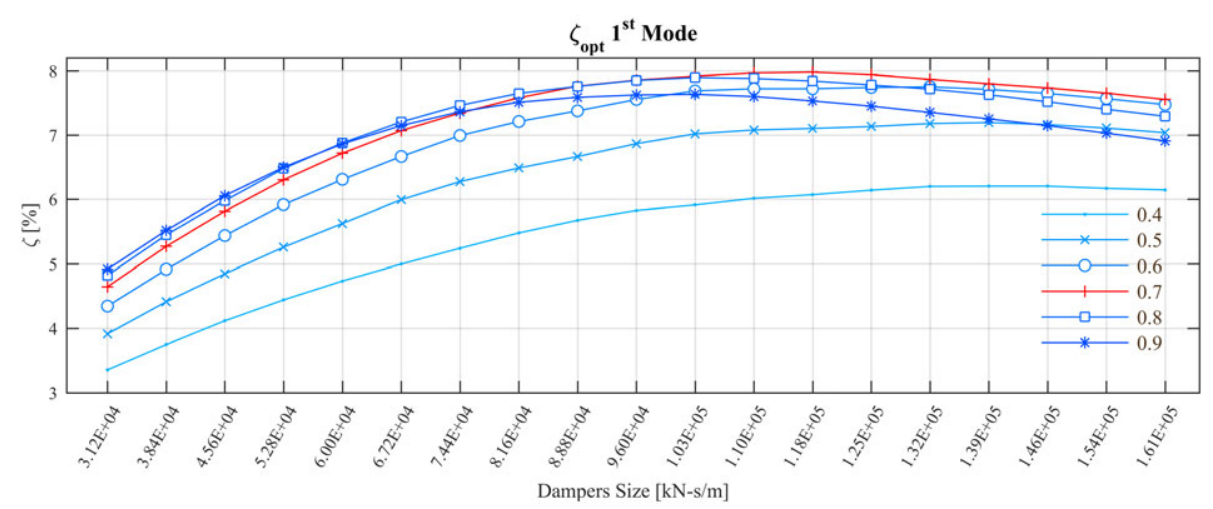

FIGURE 14 Optimal $\zeta$ according to values of $\lambda$ between 0.4 and 0.9

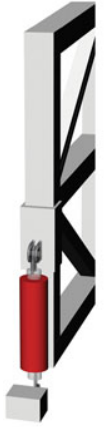

(a)

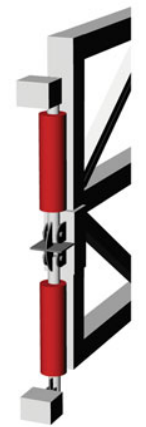

(b)

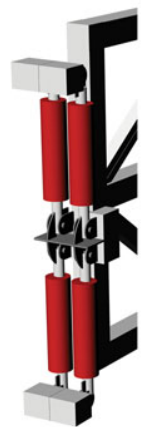

(c)

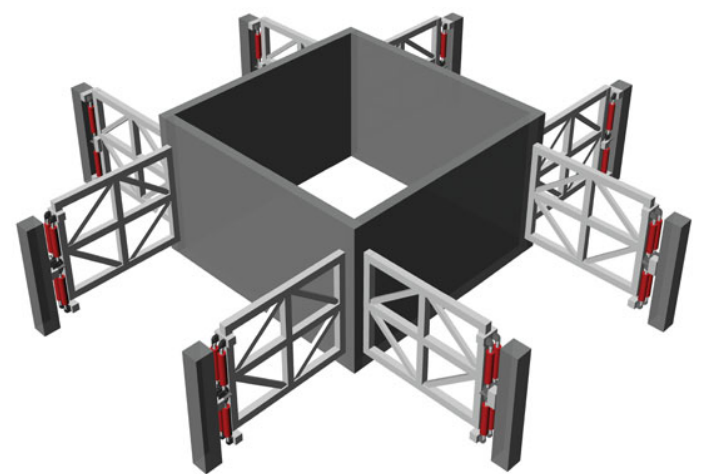

FIGURE 15 Configuration of eight outriggers with one (a), two (b), and four (c) dampers

damping may not match the optimal supplemental damping. However, the gap available-optimal could be reduced by modifying the stiffness properties of the key elements of the system, namely, core, outriggers, and perimeter columns.

Finally, it should be noted that with the addition of viscous dampers, results obtained by modal analysis are no longer fully reliable because damping may not be evenly distributed under any modal shape; analyses involving normal modes should not be used "because they cannot account for discrete damping elements within a structure, ${ }^{„ 1]}$ Furthermore, model analysis cannot be used because nonlinear response is expected. Because dampers add an important percentage of damping, response must be therefore evaluated by a full single analysis, such as a complete time-history analysis, using direct solution methods, that is, such that directly solve the dynamic equations of motion from the mass, stiffness, and damping matrices.

\subsection{Rigidity ratios core-to-outrigger $\rho_{\text {cto }}$ and core-to-column $\rho_{\text {ctc }}$}

In order to provide insights over their influence on the energy distribution and seismic response, the stiffness-based relationships core-to-outrigger and core-to-perimeter columns are studied through rigidity ratios. The rigidity ratio core-to-outrigger is a non-dimensional parameter given by Smith and Coull, ${ }^{[0]}$

$$
\rho_{c t o}=\frac{2 E l r}{(E I)_{O} H}
$$

where $(\mathrm{EI})_{\mathrm{O}}$ is the effective flexural rigidity of the outrigger, and $\mathrm{H}$ is the building's height.

The also non-dimensional rigidity ratio core-to-column is defined as follows: ${ }^{[40]}$

$$
\rho_{c t c}=\frac{E I}{2(E A)_{C} r^{2}}
$$

where $E I$ and $(E A)_{c}$ represent core and column rigidities, respectively; $r$ is the distance between the centroid of the core and the perimeter columns.

The initial FE model included a core design about 2.5 times stiffer than the combined bending and shear stiffness of the outrigger, that is, $\rho_{\text {cto }} \sim=2.5$. The core bending stiffness is about 2.25 times stiffer than the axial stiffness of the perimeter columns, that is, $\rho_{\text {ctc }} \sim=2.3$. In order to study the damping ratio sensitivity to the variation of the rigidity ratios $\rho_{\text {cto }}$ and $\rho_{\text {ctc }}$, these values were extended over a range 
between one and four. This is because values of $\rho_{\text {ctc }}$ smaller than one, although possible, are not practical from an implementation point of view, as they would require the use of columns with comparatively large cross sections in combination with a core of comparatively small wall dimensions. Values of $\rho_{\text {ctc }}>4$, on the other hand, imply that the axial stiffness of perimeter columns is less than $25 \%$ of the bending stiffness of the core. Moreover, according to the study of Tan et al., ${ }^{[7]} \rho_{\text {ctc }}$ "should not be larger than four to achieve a supplementary $5 \%$ damping level."

The results of analyses exploring the damping ratio sensitivity of the damped outrigger to the combined effect of $\lambda$, $C_{d}$, and $\rho_{\text {ctc }}$ are displayed in Figure 16. It can be seen that effect of $\rho_{\text {ctc }}$ is limited to a general $1 \%$ increase of $\zeta$, for a given $\lambda$ and $C_{d}$. However, when $\lambda$ and $C_{d}$ approximate to the optimal values, the effect of $\rho_{c t c}$ may imply an overall $\zeta$ increase in $7 \%$. This suggests that given the fact that required dampers size may not be available, a modification in the ratio $\rho_{\text {ctc }}$ will help to increase the overall damping ratio. It should be noted that such increase will only occur if $\rho_{\text {ctc }}$ decreases.

The combined influence of $\rho_{\text {cto }}$ and $\rho_{\text {ctc }}$ displayed in Figure 17, given an optimal $\lambda=0.7$, shows that the damping ratio can be further increased in $1 \%$. In addition, and as expected, peaks for each $\zeta$ show that the increase is proportional to the inherent damping ratio: $9.73 \%$ for a $\zeta_{\text {inherent }}=1.5 \%$, $10.29 \%$ for a $\zeta_{\text {inherent }}=2 \%$, and $10.82 \%$ for a $\zeta_{\text {inherent }}=2.5 \%$.

In order to understand to which extent the influence of the combined parameters $\rho_{\text {cto }}$ and $\rho_{\text {ctc }}$ is depending on either the integrated action of the viscous dampers or the modification of the fundamental building's frequency, Eigen-frequency analyses were conducted using fixed and damped outriggers. In Figure 18, the results show that frequency shift is larger in the fixed outrigger (about $0.10 \mathrm{~Hz}$ ), compared to that of the damped outrigger (about $0.6 \mathrm{~Hz}$ ). In addition, in the case of the damped outrigger, the influence of $\rho_{\text {cto }}$ is almost none and
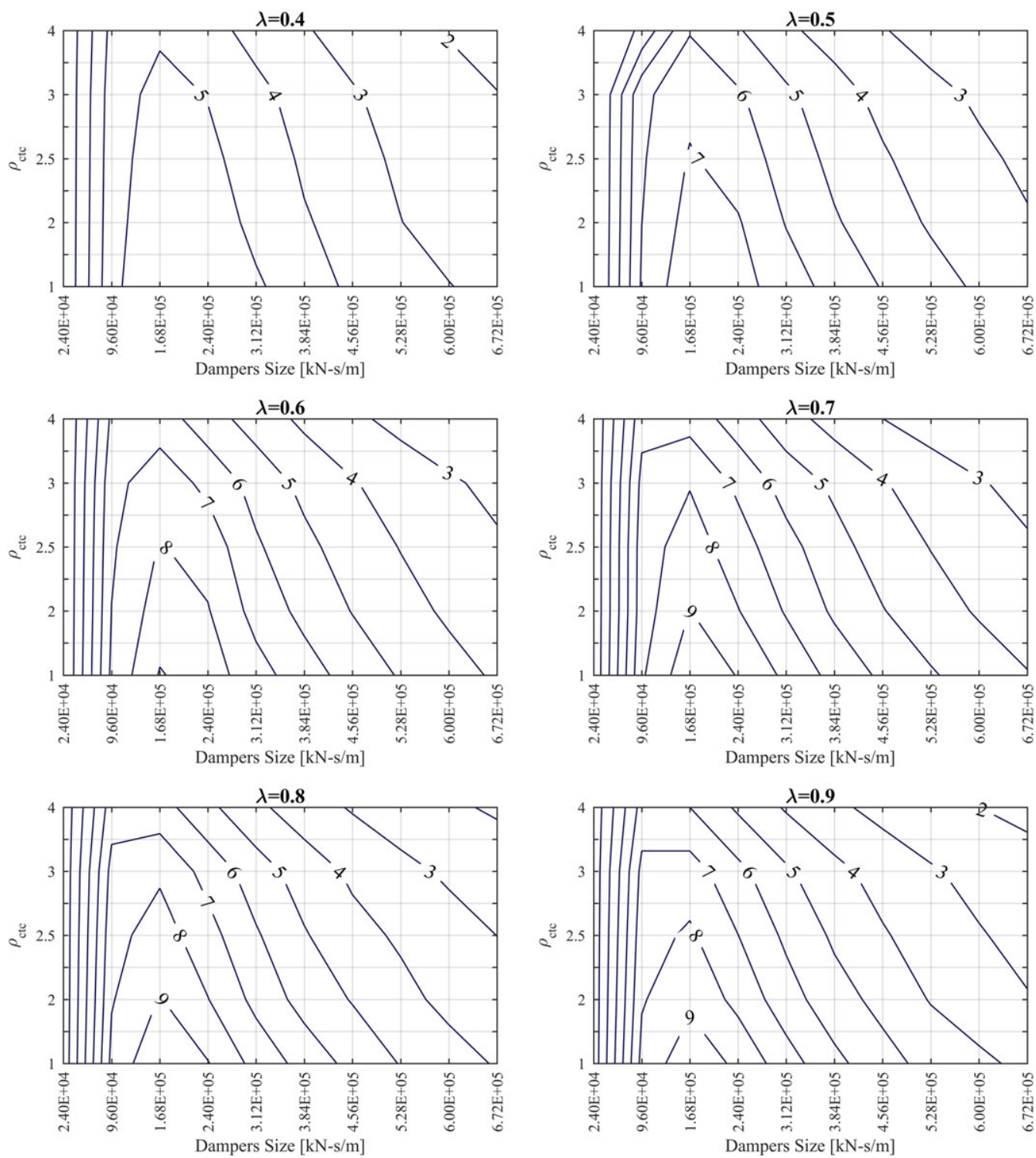

FIGURE 16 Distribution of $\zeta$ (in \%) according to variable parameters $\rho_{c t c}=1-4, C_{d}=2.40 E+04-6.72 E+05 \mathrm{kN}-\mathrm{s} / \mathrm{m}$, and $\lambda=0.4-0.9$, under free vibration. Inherent $\zeta=2 \%$ 

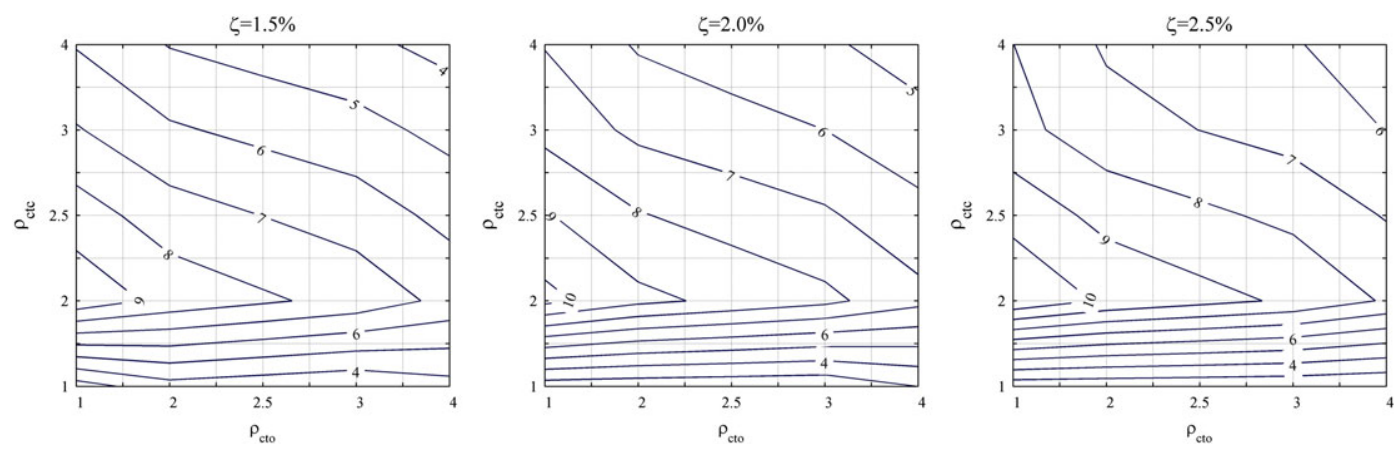

FIGURE 17 Distribution of $\zeta$ (in \%) according to initial $\zeta=1.5,2.0$, and $2.5 \% ; \rho_{\text {ctc }}, \rho_{\text {cto }}=1-4 ; \lambda=0.7$ under free vibration
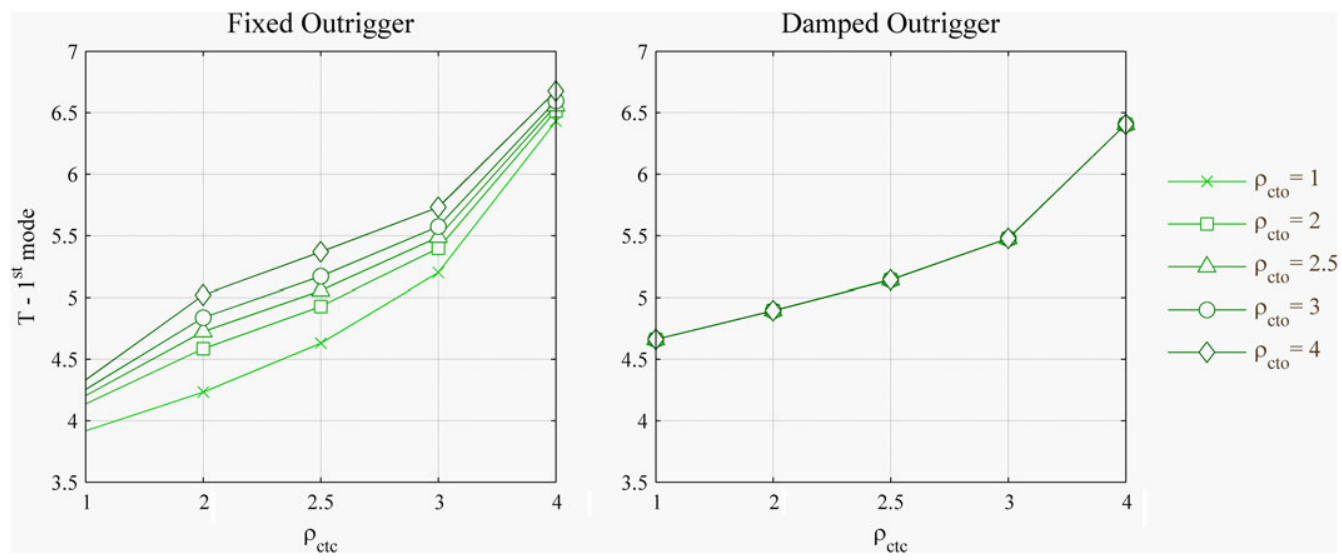

FIGURE 18 Shifts in $1^{\text {st }}$ mode period due to the combined effect of $\rho_{\text {cto }}$ and $\rho_{\text {ctc }}$ on the fixed and $1.18 \mathrm{E}+05 \mathrm{kN}-\mathrm{s} / \mathrm{m}$ damped outrigger structure; $\lambda=0.7$ and $\zeta=1.5 \%$

the frequency shift is due almost exclusively to the variation of $\rho_{\text {ctc. }}$ With the increase in $\lambda$, the outrigger exerts major influence in the frequency shift, reaching its maximum around $\lambda=0.8-0.9$ in both fixed and damped outriggers (Figure 19). It is interesting to note that none of the parameters currently under discussion, namely $\lambda, \rho_{\text {ctc }}$ and $\rho_{\text {cto }}$, have any influence on the frequency of the damped outrigger, when $\lambda<0.6$. The fact that frequency shifts become more significant as the outrigger approaches the roof, and that only $\rho_{\text {ctc }}$ has influence of such frequency shifts, supports the conclusion that both $\lambda$ and $\rho_{\text {ctc }}$ exert their influence by modifying the building's natural frequency. The fact that $\rho_{\text {cto }}$ does modifies the response but not the frequency, suggests that its influence is closely related to the effect of the viscous dampers.

Finally, the influence of the combined parameters $\rho_{\text {cto }}$ and $\rho_{\text {ctc }}$ on the seismic energy distributions was studied through time-history analyses of the damped outrigger. The results displayed in Figure 20 show that when the outrigger is flexible $\left(\rho_{\text {cto }}=4\right)$, $E_{1}$ is comparatively large regardless the modification of $\rho_{c t c}$, under all earthquake levels except severe. Under this last one, the use of a rigid outrigger $\left(\rho_{\text {cto }}=1\right)$ implies larger amount of input energy in the system. This sudden shift may be related to the assumption of the linear behaviour of the dampers: under small, moderate,
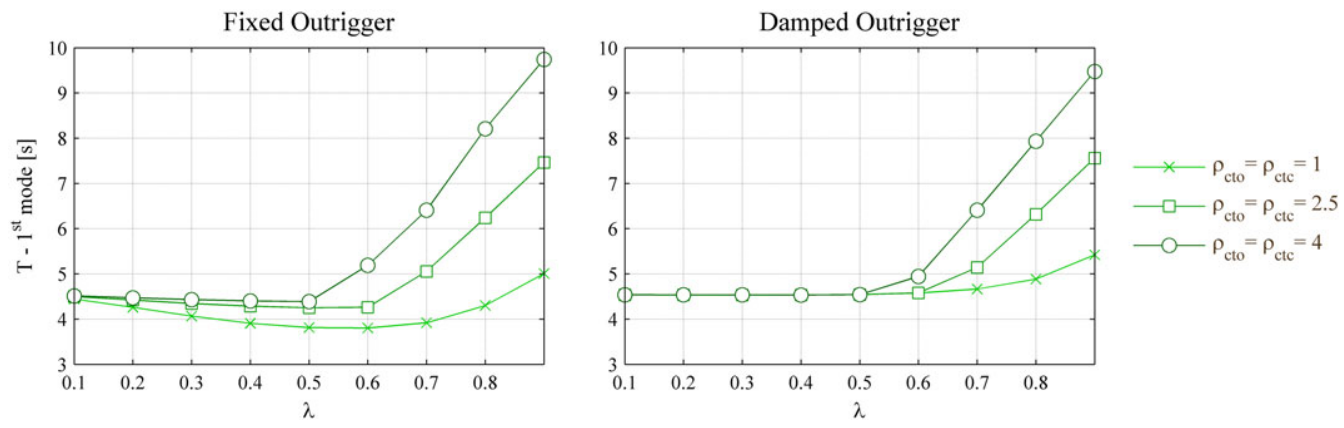

FIGURE 19 Influence of $\lambda$ in the period shifts of the fixed and damped outrigger. Data points correspond to pairs $\rho_{\text {cto }}-\rho_{\text {ctc }}=1,2.5$, and 4 

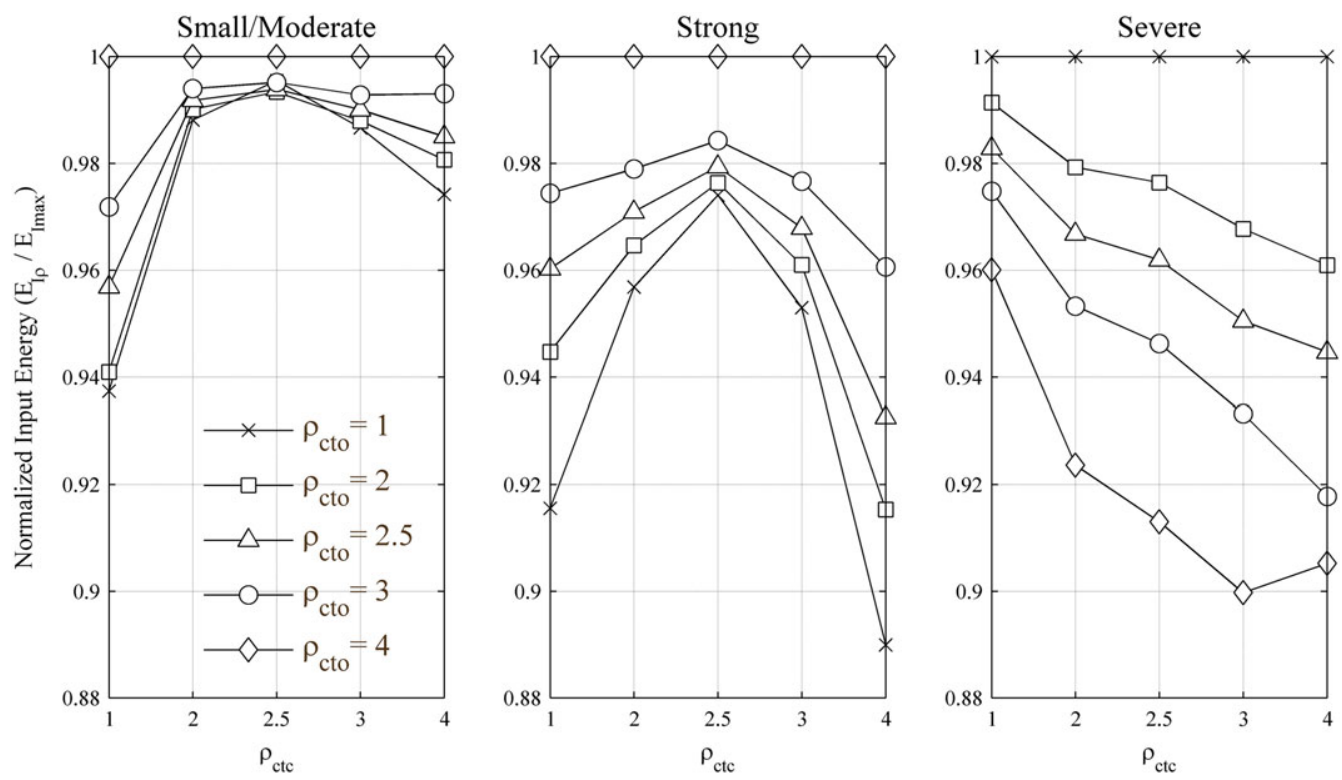

FIGURE 20 Variations of the normalized input energy $\left(E_{\mid \rho} / E_{\text {Imax }}\right)$, according to combined effect of $\rho_{\text {cto }}$ and $\rho_{\text {ctc }}$, under different earthquake levels of $1940 \mathrm{El}$ Centro earthquake; $\mathrm{C}_{\mathrm{d}}=1.18 \mathrm{E}+05 \mathrm{kN}-\mathrm{s} / \mathrm{m}, \lambda=0.7$ and $\zeta=1.5 \%$

and strong earthquakes, the velocities across the damper might not be large, and hence, the damping forces benefit from a rigid outrigger. Under severe earthquakes, the damping forces will be proportionally increased to the now large velocities, and hence, damping forces are amplified by the effect of a rigid outrigger.

\section{5 | DISCUSSION OF RESULTS}

\section{1 | Distribution of energy under strong earthquakes}

When subjected to strong ground motion, the building was modelled to undergo damage so the mechanisms of dissipating energy by hysteresis of its elements can be assessed. The appearance of plastic hinges in the structure seems to be inevitable under these types of earthquakes because as it is with the structural damping itself, the dissipation of energy by dampers increases over time. Hence, the maximum level of energy dissipation provided by dampers tends to occur towards the end of the motion, whereas kinetic energy (thus large demands over the structural flexural behaviour) occurs at the beginning of the strong motion. Assuming that parameters $\lambda$, $\rho_{\text {cto }}$, and $\rho_{\text {ctc }}$ are defined to deliver a design performing within the optimal threshold-and by such we mean in terms of energy-based performance-by the end of a given earthquake motion is expected that inherent structural damping and supplemental damping energies are balanced. In the specific case of the time-history energy ratios depicted in Figure 21 (left), the elastic response of the damped outrigger shows that during half of the motion, both damping and dampers were equally dissipating seismic energy with an increase of the dampers' energy towards the end. Whereas this information is useful to determine how much energy the dampers are dissipating, it does not give any information of how
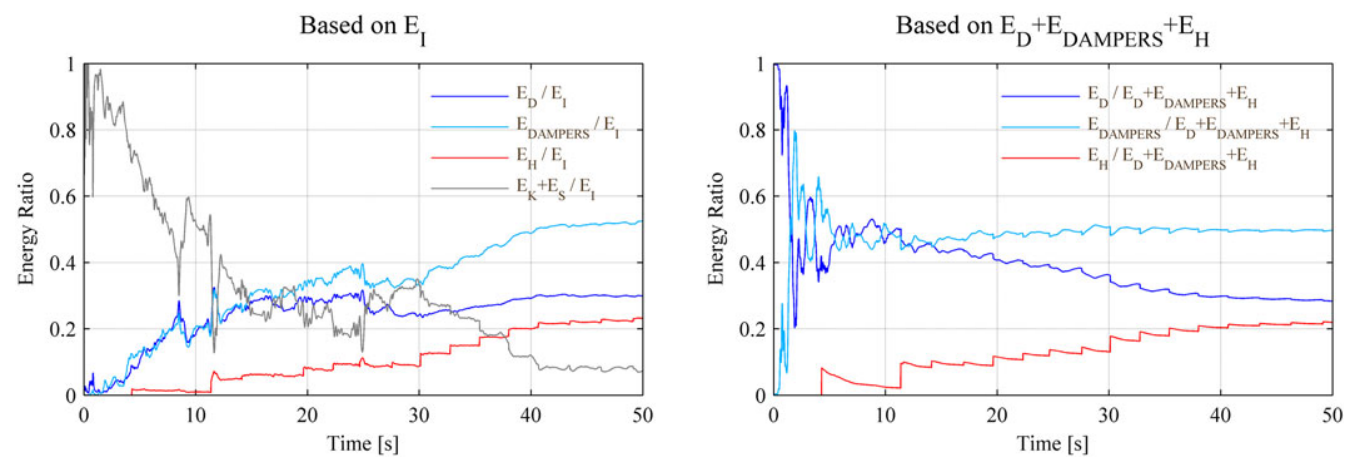

FIGURE 21 Energy ratios based on $E_{1}$ and $E_{D}+E_{\text {dampers }}+E_{H}$, for the damped outrigger under strong earthquake level of 1940 El Centro earthquake; $C_{d}=1.18 \mathrm{E}+05 \mathrm{kN}-\mathrm{s} / \mathrm{m}, \lambda=0.7$ and $\zeta=2.0 \%$ 
such energy is distributed during the first moments of the strong motions, which is when usually the structural damage tend to be produced. A second energy ratio, based on the summation of damping, dampers, and hysteretic energies, is then proposed to give information about these initial distributions. In Figure 21 (right), the same previously described time-history is depicted in terms of this relative energy ratio. Here, it can be seen the formation of "crosses" between the energy plots showing that during the motion, the energy is not constantly dissipating by one mechanism, but it alternates between damping and dampers. Perhaps not surprisingly, these crosses seem to be also related to the incursion of the structure in nonlinear behaviour, that is, with the dissipation of energy by hysteresis (Figure 22). These results suggest that an adequate balance between the $E_{D} / E_{1}$ and $E_{\text {dampers }} / E_{1}$ ratios is required to avoid plastic incursions of the structural elements during the strong motion. If the dampers dissipate the energy at expense of decreasing the inherent structural damping, the excessive stress occurring in the core and outrigger will provoke damage anyway.

The sources of such energy dissipations are vital to understand the role of dampers, core, and outriggers in the energy dissipative function. Whereas in the case of the dampers' energy, it is linked to the viscosity of the oil dampers, in the case of the damping energy, the distribution needs to be examined more in detail. In Figure 23, it can be noticed that the contribution of the outrigger to the dissipative function by inherent damping is comparatively small. This fact also explains the lack of hysteresis in the outrigger, during the strong and severe earthquake motion, when all energy dissipated by inelastic deformations occur at the core elements (Figure 24). Hence, the core is the main dissipative source of both damping and hysteretic energy. With the addition of viscous dampers, the outrigger has a minor load-bearing role, so plastic hinges concentrate on the lower zone of the core due to the action of bending and certainly the contribution of 2 nd order effects (such as P- $\Delta$ ). If, for example, due to ductility demands, plastic hinges need to be concentrated in the outrigger, its general sections can be reduced, provided that the dampers will account for the extra flexibility of the outrigger structure. The main advantage of adding viscous dampers to the outriggers is the overall reduction of stress in the members, thus increasing ductility in the structure. This leads to the conclusion that achieving elastic response under strong earthquake motions by the use of viscous dampers also requires an increase of the overall strength of the host structure. A possible solution to avoid damaging the core when employing dampers with lower damping coefficient is to increase the thickness of the core walls towards the base of the building. This common practice in the design of tall buildings' core not only avoids plasticity of the lower regions of the shear walls but also increases its flexural ductility. ${ }^{[2]}$

\subsection{Distribution of energy in conventional and damped outriggers}

The addition of supplemental damping by using viscous dampers reduces the absorbed energy in the host structure, if compared to a conventional outrigger (Figure 25). Because dampers increase the dissipative action of energy by damping, the energy that must be absorbed by hysteresis of the
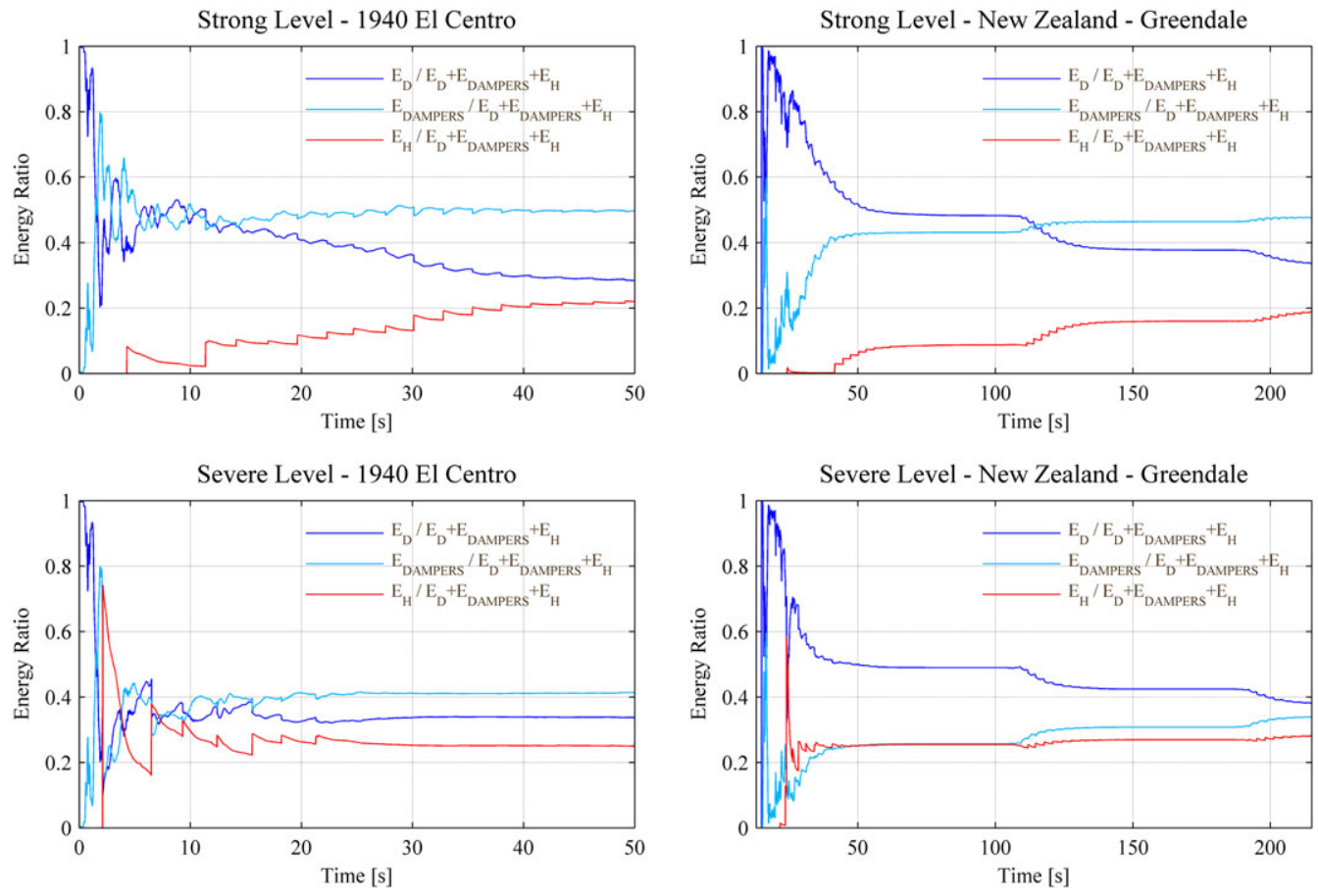

FIGURE 22 Energy ratios of the damped outrigger $\left(C_{d}=1.18 \mathrm{E}+05 \mathrm{kN}-\mathrm{s} / \mathrm{m}, \lambda=0.7\right.$ and $\left.\zeta=2.0 \%\right)$, under strong and severe levels of $1940 \mathrm{El}$ Centro and New Zealand-Greendale earthquakes 


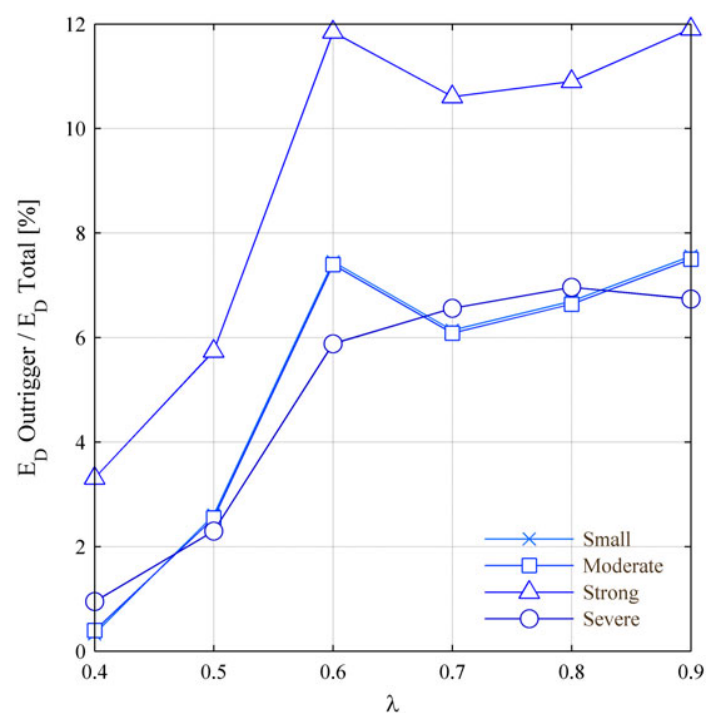

FIGURE 23 Damping energy (in \%) dissipated only by the outriggers, under the combined influence of $\lambda$ and different earthquake levels of 1940 EI Centro earthquake; $\mathrm{C}_{\mathrm{d}}=1.18 \mathrm{E}+05 \mathrm{kN}-\mathrm{s} / \mathrm{m}$ and $\zeta=2.0 \%$
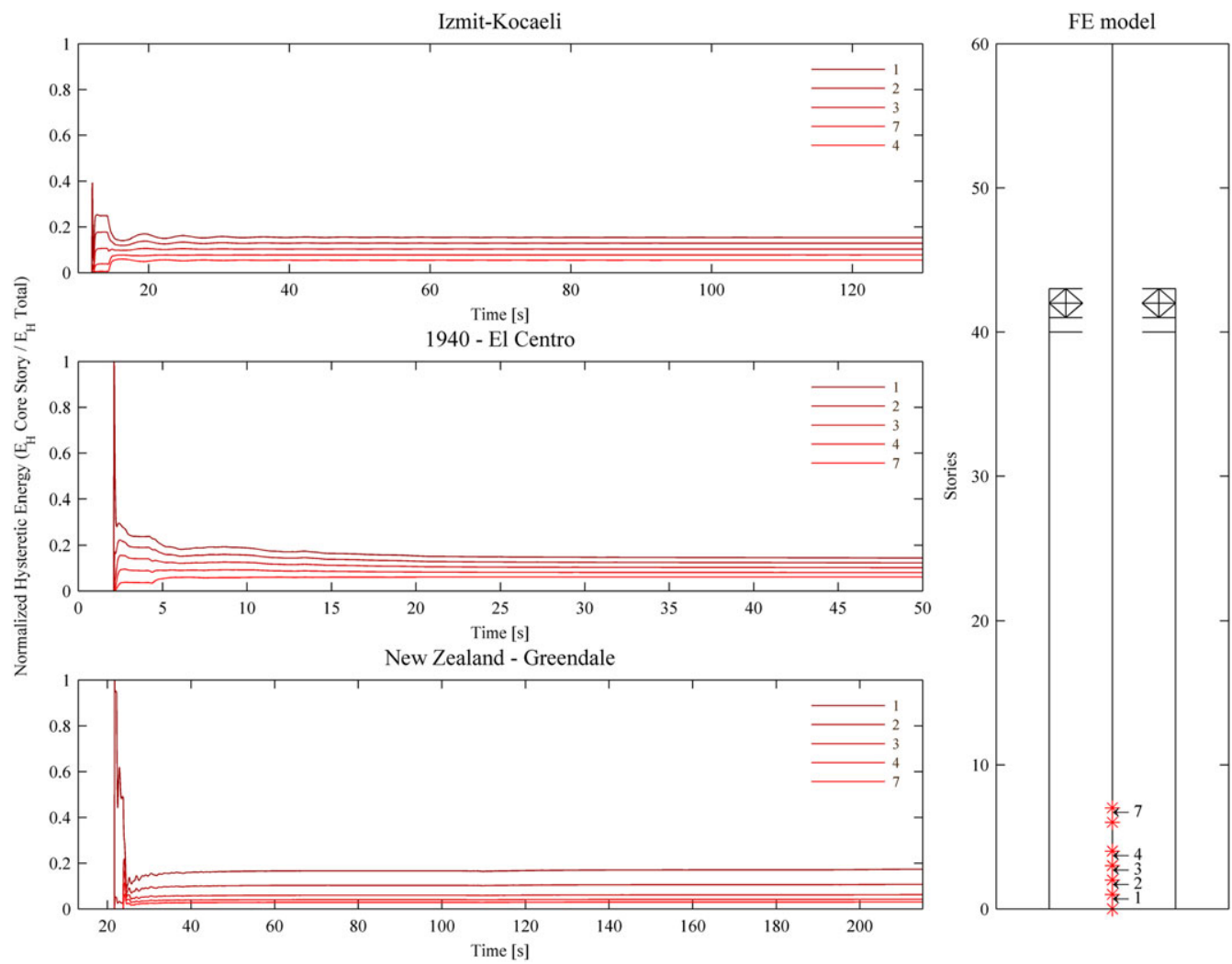

FIGURE 24 Normalized hysteretic energy dissipated by the core under severe level of Izmit-Kocaeli, 1940 El Centro, and New Zealand earthquakes. The five core elements displayed dissipated up to 50,51 , and $41 \%$ of the total hysteretic energy for each earthquake, respectively. $\left(C_{d}=1.18 \mathrm{E}+05 \mathrm{kN}-\mathrm{s} / \mathrm{m}, \lambda=0.7\right.$ and $\left.\zeta=2.0 \%\right)$

structure is reduced. This does not mean that the addition of viscous dampers directly eliminates energy dissipation by plastic deformations in the structure, but it certainly aids in its reduction (Figure 26). This later conclusion is in agreement with Zhou and Li, ${ }^{[12]}$ who developed an experimental investigation using a $7.2 \mathrm{~m}$ mock-up of a high-rise steel column-tube structure equipped with two sets of outrigger attached at roof and middle height, respectively. They concluded that the negative effect of the abrupt change of stiffness between fixed outrigger stories and adjacent stories in the inter-story drifts is decreased due to the lower stiffness of the damped outrigger. 

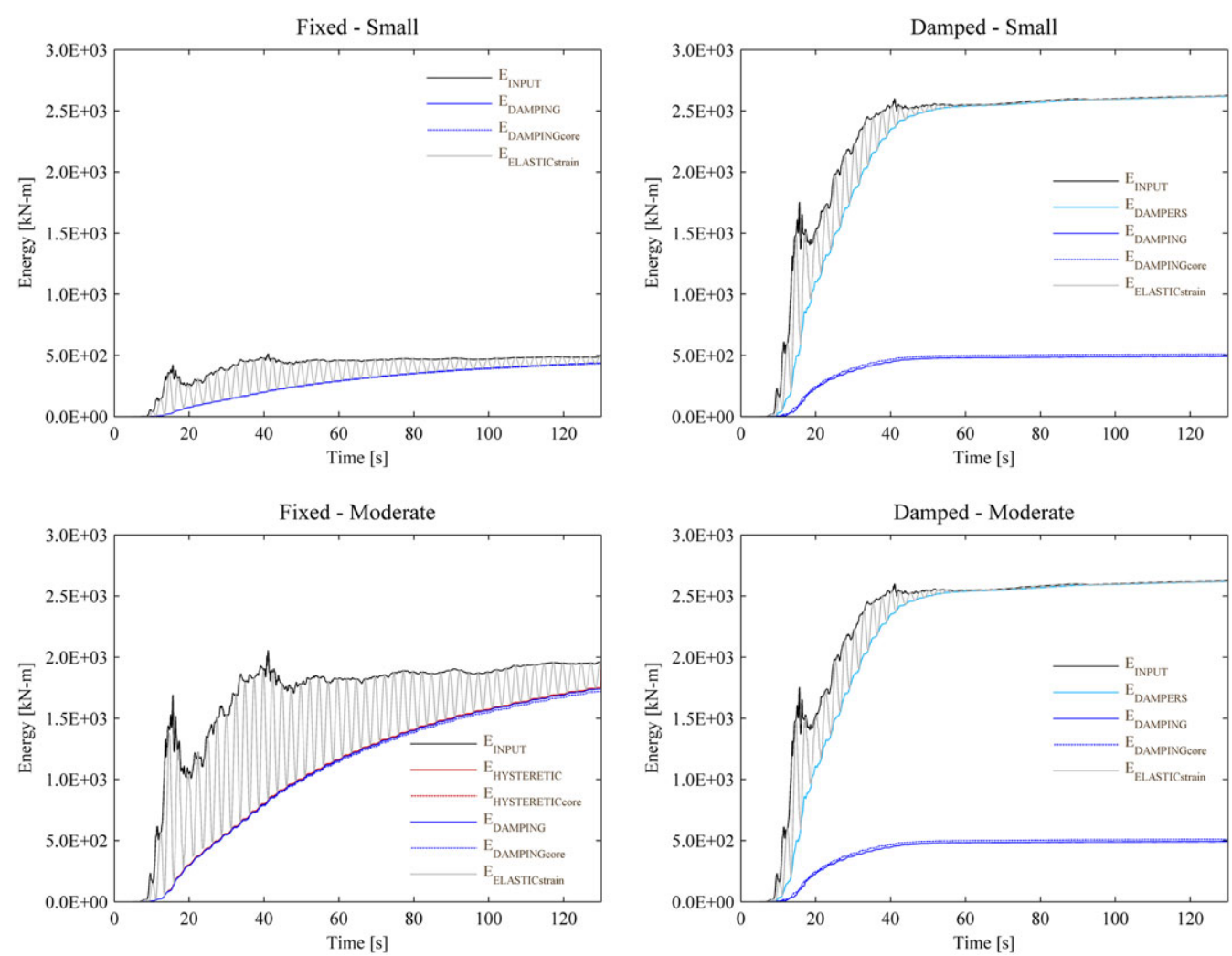

FIGURE 25 Energy distribution of the fixed and $1.18 \mathrm{E}+05 \mathrm{kN}-\mathrm{s} / \mathrm{m}$ damped outrigger structures under small and moderate levels of Izmit-Kocaeli earthquake $(\lambda=0.7$ and $\zeta=2.0 \%)$
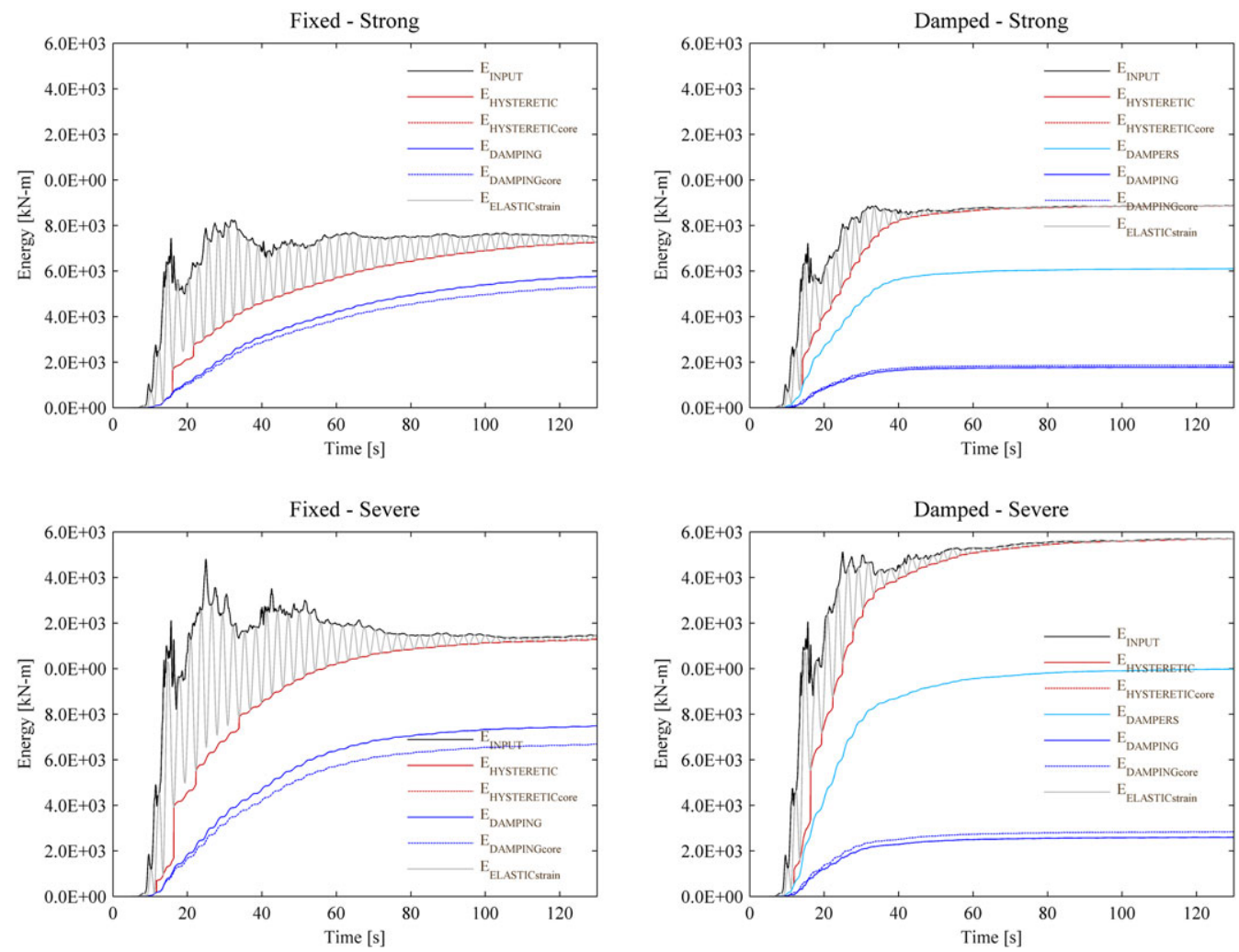

FIGURE 26 Energy distribution of the fixed and $1.18 \mathrm{E}+05 \mathrm{kN}-\mathrm{s} / \mathrm{m}$ damped outrigger structures under strong and severe levels of Izmit-Kocaeli earthquake $(\lambda=0.7$ and $\zeta=2.0 \%$ ) 
By only considering the distribution of damping energy between core and outrigger (columns were not considered as discussed previously), and plotting only the portion taken by the outriggers, it can be noted the increasing role of the outrigger in the dissipation of energy as the ground motion becomes stronger (Figure 27). Under careful observation of the responses under strong earthquake level, it is clear that the addition of dampers will reduce the damping participation ratio of the outrigger in about $5-10 \%$. Although this may suggest that outriggers do not dissipate energy as their function is replaced by the viscous dampers, it is more likely that the participation of the outrigger seems to decrease, because with the addition of dampers, the overall damping ratio would be reduced anyway. This phenomenon can be observed in Figure 28 , wherein right-plots depict energy ratios of the damped outrigger under the three selected ground motions. As it can be seen, with the addition of viscous dampers, the overall damping ratio is reduced if compared to that of the fixed outrigger. Rather important, the appearance of damage due to the increase in the
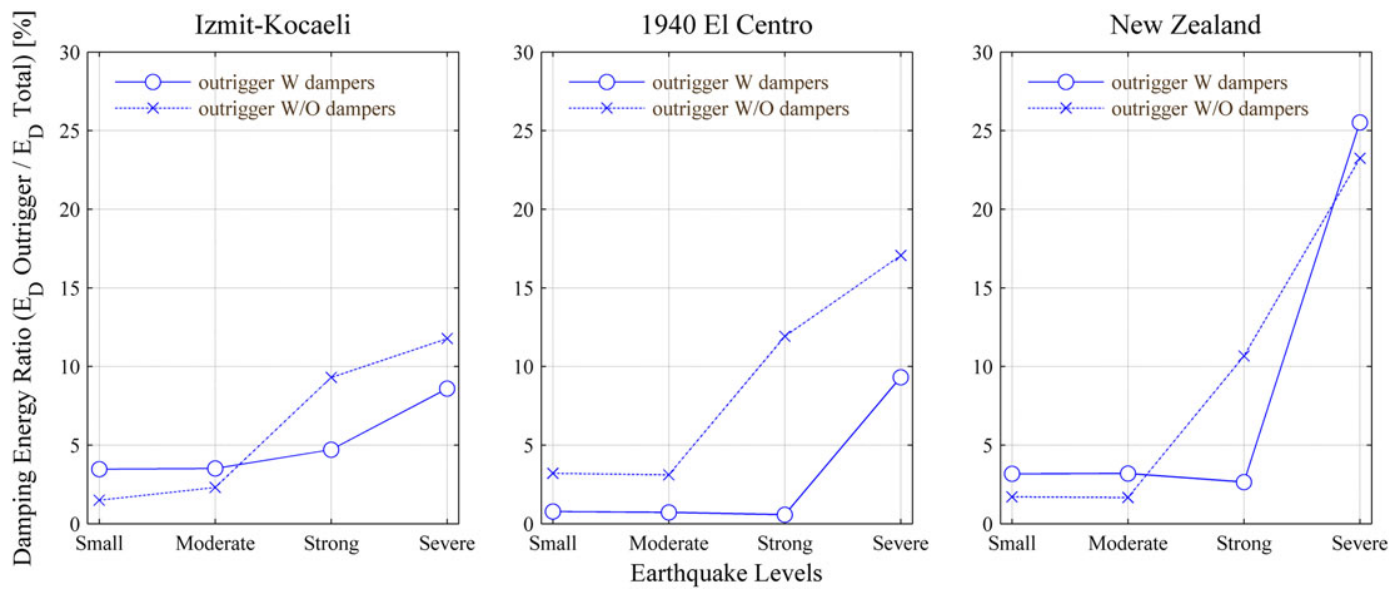

FIGURE 27 Ratios (in \%) energy dissipated by damping of outrigger with and without dampers to the total damping energy dissipated by the structure, under different earthquake levels. $\lambda=0.7, \zeta=2.0 \%$ and $C_{d}=1.18 \mathrm{E}+05 \mathrm{kN}-\mathrm{s} / \mathrm{m}$ (damped outrigger)
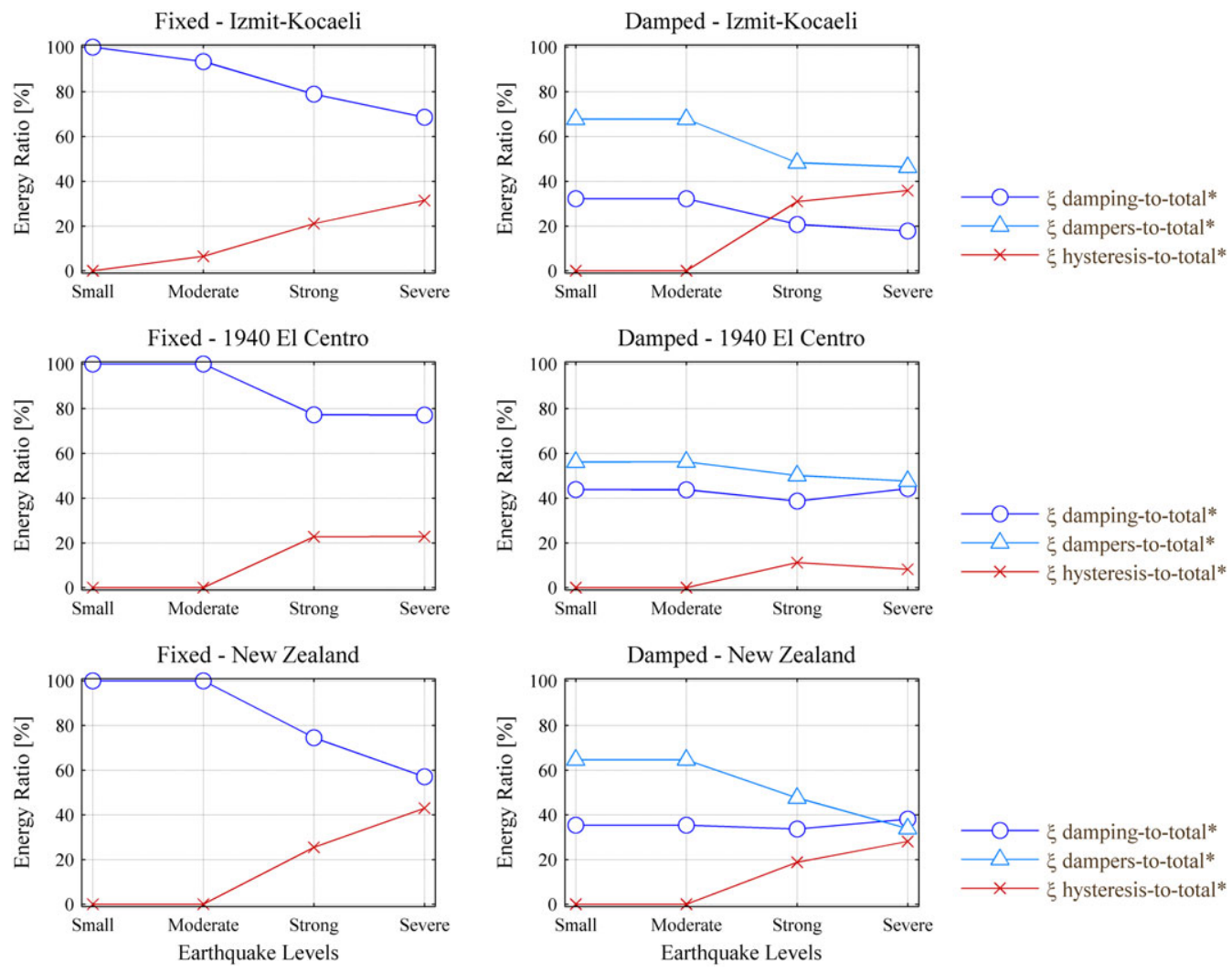

FIGURE 28 Energy ratios ( ${ }^{*}$ total $=E_{D}+E_{\text {dampers }}+E_{H}$ ) of the fixed and damped outriggers under different earthquake levels. $\lambda=0.7, \zeta=2.0 \%$ and $C_{d}=1.18 \mathrm{E}+05 \mathrm{kN}-\mathrm{s} / \mathrm{m}$ (damped outrigger) 
earthquake magnitude does not alter substantially such damping ratio, except in the case of Izmit-Kocaeli Earthquake, where the variation goes beyond $10 \%$. Moreover, the fact that only in this case the hysteretic energy is larger than in the fixed case, supports the observation that to avoid damage, the optimal design of the damped outrigger must be based on the balanced increase of both $E_{D} / E_{1}$ and $E_{\text {dampers }} / E_{1}$ ratios. Finally, plots also show that the more damage the structure undergoes, the lesser the energy the dampers dissipate.

\section{3 | Comparative performance between fixed and damped outriggers}

As previously discussed, the addition of supplemental damping in the outriggers may not significantly decrease the building response in terms of peak responses. This is the case for the normalized inter-story drift response as depicted in Figure 29, where except for the case under El Centro Earthquake, the differences between fixed and damped responses are not significant. In the case of the base shear, as depicted in Figure 30 , results display a similar fixed-damped trend except in the case of the outrigger subjected to New Zealand earthquake. This comparatively large reduction in the base shear could be related to its PGV, which is the highest among the ground motions used in this study. Nevertheless, given the fact that aforementioned plots display the results of optimal outrigger structures, it seems clear that neither inter-story drifts nor base shear are substantially reduced with the addition of viscous dampers to the outriggers.

Although peak overturning moment and stresses might not occur at the same instant during the earthquake motion, plots displaying the relationship between these two peaks were elaborated to study whether the addition of dampers help to reduce the structural response. From the plots displayed in Figure 31, it is clear that, under optimal design conditions, the addition of viscous dampers reduces both the overturning moment and overall stresses in core, outriggers, and perimeter columns. Moreover, by helping to reduce the overall stress, the use of viscous dampers prevents the extension of damage as the ground motion grows larger, if compared with the response of the fixed outrigger. Finally, all the damage
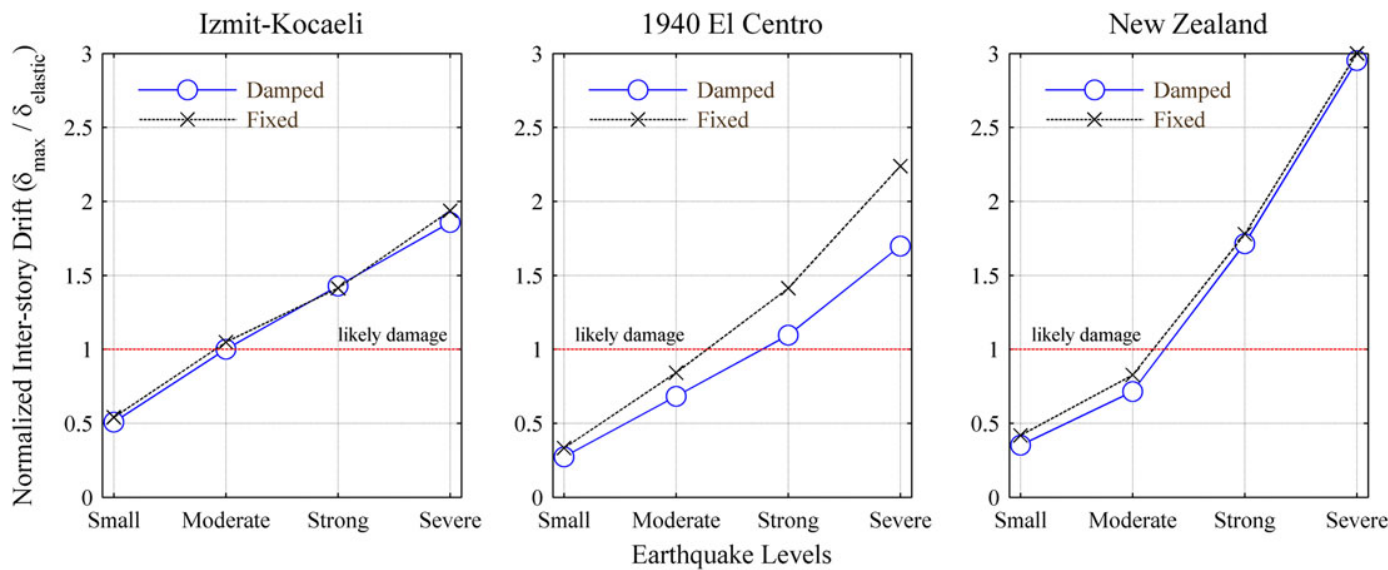

FIGURE 29 Normalized inter-story drift (maximum/elastic) of the fixed and damped outriggers under different earthquake levels. $\lambda=0.7, \zeta=2.0 \%$ and $\mathrm{C}_{\mathrm{d}}=1.18 \mathrm{E}+05 \mathrm{kN}-\mathrm{s} / \mathrm{m}$ (damped outrigger)
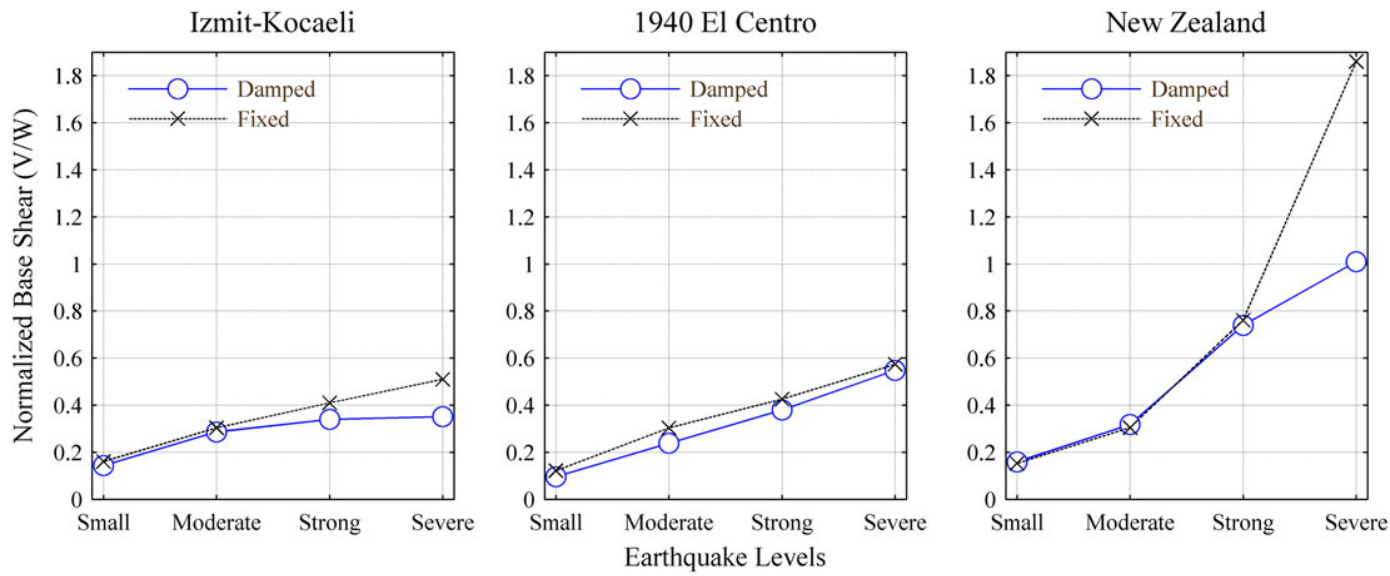

FIGURE 30 Normalized base shear $(\mathrm{V})$ over seismic mass $(\mathrm{W})$ of the fixed and damped outrigger under different earthquake levels. $\lambda=0.7, \zeta=2.0 \%$ and $\mathrm{C}_{\mathrm{d}}=1.18 \mathrm{E}+05 \mathrm{kN}-\mathrm{s} / \mathrm{m}$ (damped outrigger) 

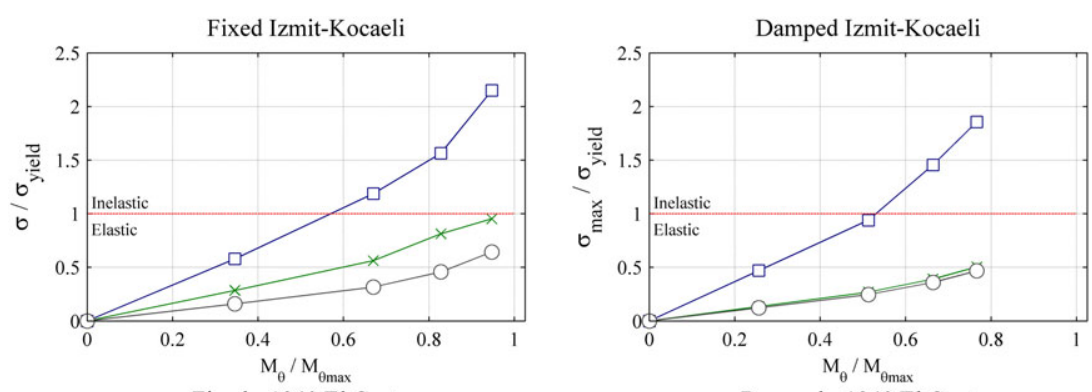

$$
\begin{aligned}
& -\star \sigma_{\max } \text { Outrigger } \\
& -\square-\sigma_{\max } \text { Core } \\
& -0-\sigma_{\max } \text { Column }
\end{aligned}
$$
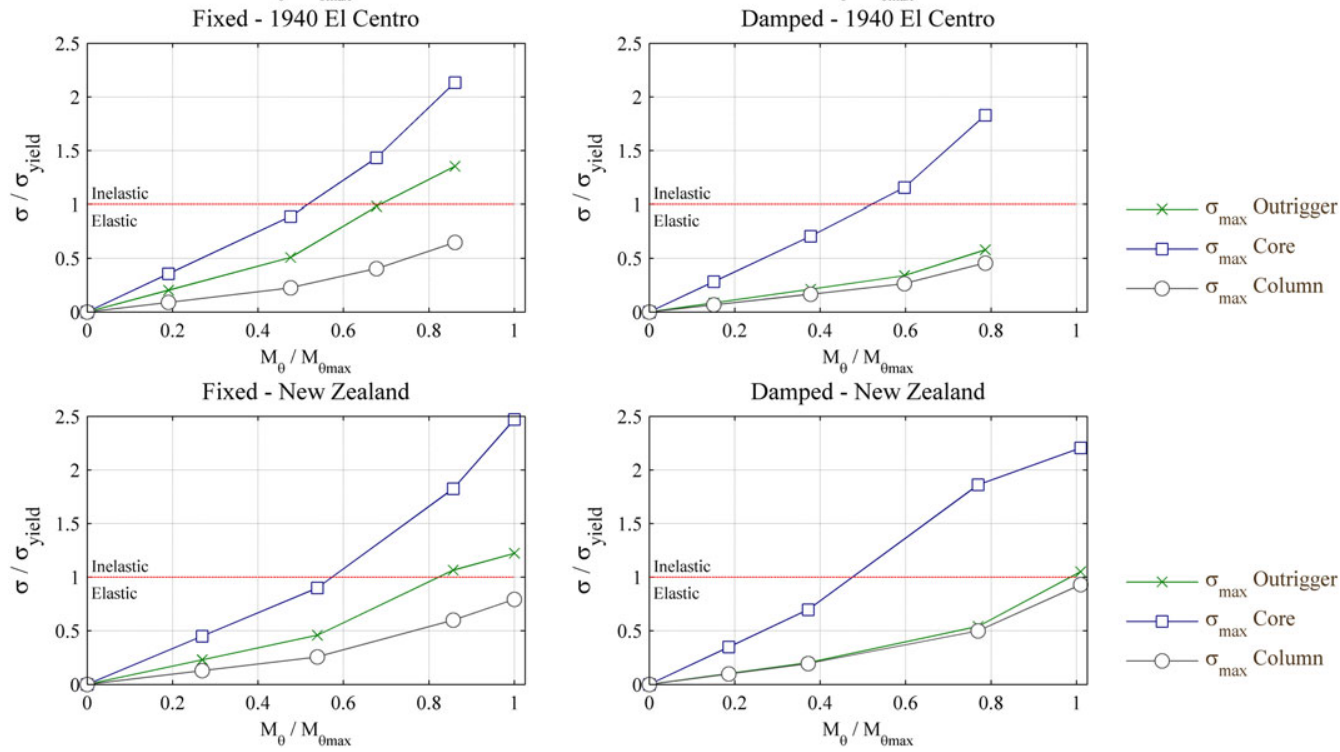

FIGURE 31 Normalized stress (actual/yield) to normalized overturning moment of the fixed/damped outrigger structures under different earthquake levels. $\lambda=0.7, \zeta=2.0 \%$ and $C_{d}=1.18 \mathrm{E}+05 \mathrm{kN}-\mathrm{s} / \mathrm{m}$ (damped outrigger)

induced by the different levels of earthquake in the outriggers equipped with dampers is concentrated in the core, provoked by the overpass of the tensile strength, that is, by yielding of the longitudinal reinforcement. In the case of damage in the outrigger, the compressive strength was overpassed producing buckling in some of the braces and/or chords.

\section{6 | CONCLUSIONS}

An explorative study on the parameters that influence the distribution of seismic energy in outrigger structures is been presented. Although most of the conclusions obtained are only applicable to the specific cases described in this paper, general observations can be derived from the numerical studies presented herein, as follows:

- As the ground motion becomes stronger, viscous dampers effectively reduce the potential of damage in the structure if compared to conventional outriggers.

- The addition of viscous dampers to the outriggers, under optimal design conditions, reduce the overturning moments and stresses of the main components of the system, that is, core, outriggers, and perimeter columns, under strong earthquakes-if compared to a conventional outrigger.

- Dampers cannot, however, reduce completely the damage under critical earthquakes because the peak $E_{H} / E_{1}$ usually precedes the peak $E_{\text {dampers }} / E_{1}$.

- Hysteretic energy is concentrated in the core, whose damage is provoked by the overpass of the tensile strength.

- Combined $C_{d}$ and $\lambda$ have a major influence in the increase of $\zeta$ and in the overall response of the outrigger structure. If required supplemental damping is not achievable in practice, modification of the ratio rigidity $\rho_{\text {cto }}$ and $\rho_{\text {ctc }}$ may help to reduce the gap between demand and supply of supplemental damping.

- It can be assumed that viscous damper outrigger structures exhibit a comparatively improved performance if subjected to long-period ground motions. Nevertheless, this preliminary conclusion must be further investigated by extending the analyses under an extended set of ground motion records. 
The study presented here considered a single outrigger scheme. The advantages of using two or more outriggers to reduce the structural damage under strong earthquakes will be addressed in further studies. Finally, because viscous dampers are not able to properly dissipate the earthquake input energy at the beginning of the ground motion, other control schemes might be investigated to prompt the supplemental damping at the initial stages of the strong motion. Active or semi-active damped devices may be suitable to act before the energy begins to be dissipated through non-elastic responses of the structure.

\section{ACKNOWLEDGEMENTS}

The authors thank the anonymous referees for their valuable comments and suggestions that helped to improve this paper. The first author's work in this research is supported by the Comisión Nacional de Investigación Científica y Tecnológica through the project BecasChile (grant 72100284). This support is gratefully acknowledged.

\section{ORCID}

M. Morales-Beltran (iD http://orcid.org/0000-0003-4883-4314

\section{REFERENCES}

[1] R. Smith, M. R. Willford, Struct. Design Tall Spec. Build. 2007, 16(4), 501.

[2] M.R. Willford, R. Smith. in Proceedings of the 14th world conference on earthquake. Engineering, (14WCEE). (Eds: Beijing, China), $2008,8$.

[3] K. Park, D. Kim, D. Yang, D. Joung, I. Ha, S. Kim, International Journal of Steel Structures 2010, $10(4), 317$.

[4] R. Smith, International Journal of High-Rise Buildings 2016, 5(1), 63.

[5] B. Huang, T. Takeuchi, Earthquake Spectra 2017, 33(2), 665.

[6] C. J. Fang, P. Tan, C. M. Chang, F. L. Zhou, Struct. Design Tall Spec. Build. 2015, 24(12), 797.

[7] P. Tan, C. Fang, F. Zhou, Earthq. Eng. Eng. Vib. 2014, 13(2), 293.

[8] T. Asai, C. M. Chang, B. M. Phillips, B. F. Spencer Jr., Eng. Struct. 2013, 57(0, 177.

[9] K. Deng, P. Pan, A. Lam, Y. Xue, Struct. Design Tall Spec. Build. 2014, 15, 1158.

[10] J. C. O'Neill, in Application of damping in high-rise buildings, in Dept. of Civil and. Environmental Engineering, (Ed: Massachusetts Institute of Technology) 2006.

[11] Z. Wang, C. M. Chang, B. F. Spencer Jr., Z. Chen, in SPIE Smart Structures and Materials+ Nondestructive Evaluation and Health Monitoring, (Ed: Eds: International Society for Optics and Photonics) $201076473 Z$.

[12] Y. Zhou, H. Li, Struct. Design Tall Spec. Build. 2013, 23(13), 963.

[13] Y. Zhou, C. Zhang, X. Lu, Struct. Control. Health Monit. 2017, 24(1), e1864.

[14] C. M. Chang, Z. Wang, B. F. Spencer Jr., Z. Chen, Smart Structures and Systems 2013, 11(5), 435.

[15] H.-S. Kim, J.-W. Kang, Journal of Asian Architecture and Building Engineering 2017, 16(1), 201.

[16] Y. Zhou, C. Q. Zhang, X. L. Lu, Proceedings of the 10th national conference in earthquake engineering. (Eds: E.E.R. Institute, Anchorage, Alaska 2014.

[17] R. Gamaliel, Frequency-based response of damped outrigger systems for tall buildings, in Dept. of Civil and. Environmental Engineering. 2008, Massachusetts Institute of Technology.

[18] P. Khashaee, B. Mohraz, F. Sadek, H. Lew, J.L. Gross, Distribution of earthquake input energy in structures. 2003, U.S. Department of Commerce: Gaithersburg.

[19] C. M. Uang, V. V. Bertero, Earthq. Eng. Struct. Dyn. 1990, 19(1), 77.

[20] H. Beiraghi, A. Kheyroddin, M. A. Kafi, Struct. Design Tall Spec. Build. 2016, 25(15), 801.

[21] X. Lu, X. Lu, H. Sezen, L. Ye, Eng. Struct. 2014, 67, 109.

[22] B. Akbas, J. Shen, H. Hao, Struct. Des. Tall Build. 2001, 10(3), 193.

[23] L. D. Decanini, F. Mollaioli, Soil Dyn. Earthq. Eng. 2001, 21(2), 113.

[24] E. Bojórquez, A. Reyes-Salazar, A. Terán-Gilmore, S. Ruiz, Compos. Struct. 2010, 10(4), 331.

[25] A. Yanik, U. Aldemir, M. Bakioglu, International Journal of Computational Methods and Experimental Measurements 2014, 2(1), 14.

[26] K. Wong, J. Johnson, J. Eng. Mech. 2009, 135(4), 265.

[27] M. Panagiotou, J. I. Restrepo, Earthq. Eng. Struct. Dyn. 2009, 38(12), 1359.

[28] H. Beiraghi, N. Siahpolo, Struct. Design Tall Spec. Build. 2017, 26(2) e1306.

[29] DIANA-FEA, in Element Library, in DIANA-User's Manual release 9.5, (Eds: J. Manie, W. P. Kikstra), Delft, The Netherlands 2014, TNO DIANA bv.

[30] B. S. Taranath, Structural analysis and design of tall buildings, McGraw-Hill, New York 1988.

[31] EN1992-1-1, Eurocode 2: Design of concrete structures - part 1-1: General rules and rules for buildings, E.C.f.S. (CEN), Editor. 2004.

[32] EN1993-1-1, Eurocode 3: Design of steel structures - part 1-1: General rules and rules for buildings, E.C.f.S. (CEN), Editor. 2004.

[33] Y. Boivin, P. Paultre, Can. J. Civ. Eng. 2012, 39(7), 738.

[34] PEER/ATC, Modeling and acceptance criteria for seismic design and analysis of tall buildings, in PEER/ATC 72-1, Redwood City, CA 2010.

[35] CESMD, Strong-motion virtual data center. 2014. (Accessed Sep-2014 www.strongmotioncenter.org)

[36] M. Bruneau, N. Wang, Eng. Struct. 1996, 18(1), 1. 
[37] A. K. Chopra, Dynamics of structures: theory and applications to earthquake engineering, Prentice-Hall 2007.

[38] INN. Instituto de Normalización, NCh 433-of. 96 Diseño sísmico de edificios., INN-CHILE, Santiago, Chile 2005.

[39] J. Hoenderkamp, Struct. Design Tall Spec. Build. 2004, 13(1), 73.

[40] B.S. Smith, A. Coull, Tall building structures: analysis and design. 1991

[41] Y. Chen, D. McFarland, Z. Wang, B. Spencer, L. Bergman, J. Struct. Eng. 2010, 136(11), 1435.

[42] J. R. Wu, Q. S. Li, Struct. Design Tall Spec. Build. 2003, 12(2), 155.

[43] S. Infanti, J. Robinson, R. Smith, in 14th World Conference on Earthquake. Engineering, (14WCEE), (Ed: Eds: Beijing, China) 20088.

[44] M. Morales-Beltran, G. Turan, U. Yildirim, in 16th World Conference on Earthquake. Engineering, (16WCEE), (Ed: Eds: Santiago, Chile) 201712.

Mauricio Morales-Beltran PhD. Researcher in Structural Design at the Faculty of Architecture and the Built Environment at Delft University of Technology in the Netherlands. Senior Lecturer at Faculty of Architecture at Yaşar University, Izmir-Turkey. He obtained his M.Eng from Universidad Mayor and B.Arch from Catholic University of the North, both in Chile.

Gürsoy Turan, Assistant Professor, İzmir Institute of Technology-Department of Civil EngineeringBSc. (Middle East Technical University), MSc., PhD (University of Illinois at Urbana-Champaign)Research Interests:Structural Dynamics and Active Control, Structural Analysis

Umut Yıldırım was born in Izmir, Turkey. He obtained his Bachelor's degree from Celal Bayar University, Manisa, Turkey. He completed MSc degree in Civil Engineering programme at İzmir Institute of Technology. His master thesis was entitled as "Earthquake Response of R/C Frames with Reinforced Infill Walls." Later, he was admitted and involved in a research project as a researcher due to exploring the potentialities of sandwich slab that consists of Glass Fibre Reinforced Polymer (GFRP) profile and Fibre Reinforced Concrete (FRC) in Structural Sustainability Group (ISISE) at University of Minho, Portugal. He obtained his PhD degree from University of Pavia, Italy, which was entitled as "System identification towards diagnosis to prognosis" under the supervision of Prof. Casciati. He was involved as a Marie Curie researcher in EU/FW7 SmartEN research project. His research expertise are mainly structural control, system identification, data compression, prediction, damage detection, and different types of parameter estimation methods. He is currently an Assistant Professor in Civil Engineering Department at Eastern Meditarrain University, North Cyprus.

Joop Paul is professor of Structural Design at the Faculty of Architecture and the Built Environment. Joop Paul is an expert in the field of earthquake-resistant design. Besides being a professor, Joop Paul is a constructor and director at the international design and engineering firm Arup. He is experienced in designing super high-rise buildings, buildings with multifunctional programmes and complex geometry. He regularly collaborates with national and international top-class architects and artists.

How to cite this article: Morales-Beltran M, Turan G, Yildirim U, Paul J. Distribution of strong earthquake input energy in tall buildings equipped with damped outriggers. Struct Design Tall Spec Build. 2018;27:e1463. https://doi.org/10.1002/tal.1463 